\title{
Predicting the mechanical properties of date palm wood fibre-recycled low density polyethylene composite using artificial neural network
}

\author{
Clement Uche Atuanya ${ }^{1}$, Mike Rabboni Government ${ }^{2}$, Chidozie Chukwuemeka Nwobi-Okoye ${ }^{3 *}$ \\ and Okechukwu Dominic Onukwuli ${ }^{4}$
}

\begin{abstract}
Background: Experimental determination of properties of engineering materials is quite expensive and time consuming. Computational methods of predicting the properties of materials, such as artificial neural network (ANN), are easier and bereft of complex mathematics that characterizes analytical methods. Also, Nigeria consumes a lot of bottled and sachet water. Most of the bottles and sachets are made with low density polyethylene (LDPE) and these sachets constitute a major source of pollution in Nigerian cities and towns. In addition, date palm is a major cash crop in Nigeria.

Methods: In this study, an artificial neural network (ANN) approach is used to predict the mechanical properties of date palm wood fiber-recycled low density polyethylene composite. In the artificial neural network, multi layer perceptron architecture (MLP) with back-propagation is utilized. In ANN training module, the ground fibres weight percent (wt \%) was used as input for various particles sizes (150,212, 250 and $300 \mu \mathrm{m})$. The outputs consist of the ultimate tensile strength, elongation, tensile modulus, flexural strength, flexural modulus and hardness for the particle sizes: 150, 212, 250 and $300 \mu \mathrm{m}$. The artificial neural network system was trained using the prepared training set. After the training process, the test data were used to check the system accuracy.
\end{abstract}

Results: The correlation coefficients of all predictions with experimental values were more than 0.99 .

Conclusion: These results show that artificial neural network is very successful in the prediction of the mechanical properties.

Keywords: Artificial neural network; Polymer composite; Mechanical properties; Material testing; Simulation; Modelling

\section{Background}

Inorganic materials have been used as fillers in the polymer industry for production of composites. These materials face some problems such as

- High density

- High cost of production

- High cost of raw material procurement

- Not easily available

- Abrasive to the processing equipment

- Low specific properties

- Low insulating properties

* Correspondence: chidozien@yahoo.com

${ }^{3}$ Anambra State University, Uli, Nigeria

Full list of author information is available at the end of the article
Due to these enumerated reasons, organic fillers are increasingly being considered in composite production. Hence, date palm wood was used as filler to develop the polymer composite used in this work. Mechanical properties of materials are extremely important and determine the quality of the material with respect to its application to engineering. Polymer composites are a very important class of engineering materials.

Nigeria is in the tropics and borders the Sahara Desert. Date palms are abundant in Northern Nigeria. Large quantities of date palm nuts are consumed in Nigeria either directly as food or indirectly as raw material in food and agrobased industries (AbdulQadir et al. 2011). Information on date palm production levels in nine states in Nigeria reveals that date palm production is increasing. The states are Bauchi 6,000 metric tons, Adamawa 600 metric tons, Borno 
1,000 metric tons, Gombe 1,500 metric tons, Jigawa 5,000 metric tons, Kano 6,000 metric tons, Plateau 100 metric tons, Taraba 200 metric tons and Yobe 2000 metric tons (Nigerian Institute for Oil Palm Research 2008). As the level of production of date palm increases, the waste from it increases as well. The conversion of the waste to useful material will whittle down the impact of the waste to the environment. Again, the geographic location of date palm may influence the property of the resultant composite. In this work, particle size and particle loading were varied since mechanical properties depend strongly on them (Shao-Yun et al. 2008).

Secondly, Nigeria consumes a lot of bottled and sachet water. Most of the bottles and sachets are made with lowdensity polyethylene (LDPE), and these sachets constitute a major source of pollution in Nigerian cities and towns (Atuanya 2013), thanks to the volume of waste from recycled low-density polyethylene sachets used for packaging potable water generated in Nigeria which rose up to 22.4 million tons in 2012 (Akinro et al. 2012). Our choice of recycled LDPE is borne out of environmental consideration, as LDPE from sachets disposed from consumed water sachets constitutes environmental hazards in our towns, cities and villages.

The literature is replete with works done on the use of date palm fibre as fillers for composites. For instance, Sbiai et al. (2008) used epoxy as the matrix in a composite developed with date palm fibres and investigated the effect of fibre sizes on the physicochemical and mechanical properties (flexural and tensile). They reported improved mechanical properties in both the linear and non-linear range upon addition of date palm tree fibres, especially when the shorter fibres were used. Al-Kaabi et al. (2005) investigated the potential of natural fibre extracted from the date palm tree as reinforcement for polyester matrix composites. Their results show that these fibres may yield reasonable properties and could be used for low-cost applications that require low to medium strength. Mahdavi et al. (2010) compared the mechanical properties of composites made from various fibres extracted from date palm and high-density polyethylene. Bendahou et al. (2008) used

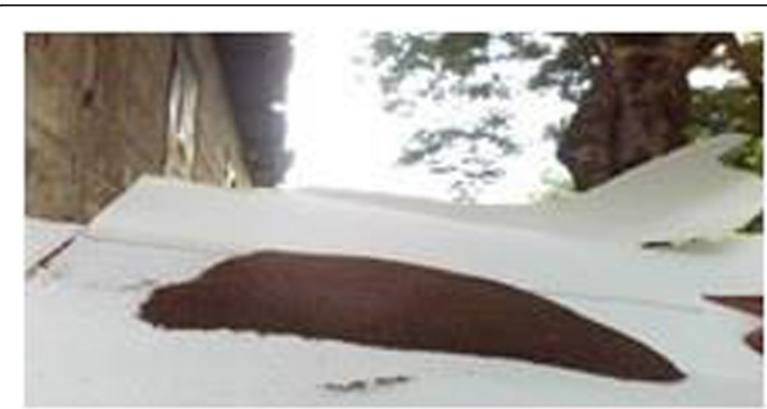

Figure 1 Date palm wood flour. compatibilized low-density polyethylene and polypropylene as matrices for a data palm fibre-based composite. They characterized morphology and thermal and mechanical properties of the resulting composites using SEM, DSC and tensile tests. They reported that compatibilization enhanced the mechanical performances for both sets of composites up to a critical amount of compatibilizer, beyond which the degree of crystallinity of the matrix decreases. Other works where date palm fibre is used as fillers for polymer composites include Wazzan (2005), Al-Khanbashi et al. (2005), etc. From the literature, it is apparent that percentage composition, particle sizes and type of fillers affect the mechanical properties of composites. One of the ways this work differs from the others mentioned above is that we used recycled low-density polyethylene for our study and investigated the effect of fibre sizes and percentage composition on six mechanical properties of the composite.

Traditionally, laboratory trial mixes have been used to determine the mechanical properties of polymer composites, as well as other engineering materials. Experimental determination of mechanical properties of materials is costly and time-consuming. Finding a potable low-cost way of predicting the strength of polymer composite materials would help in solving the problem (Nwobi-Okoye et al. 2013;

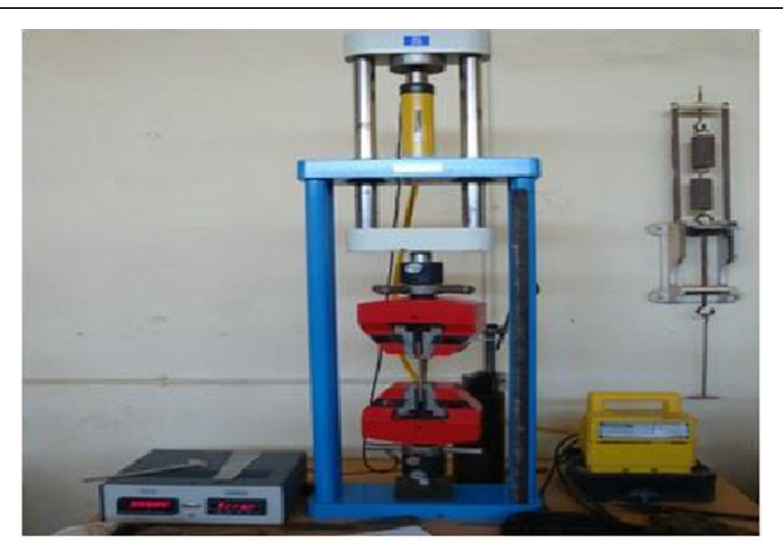

a

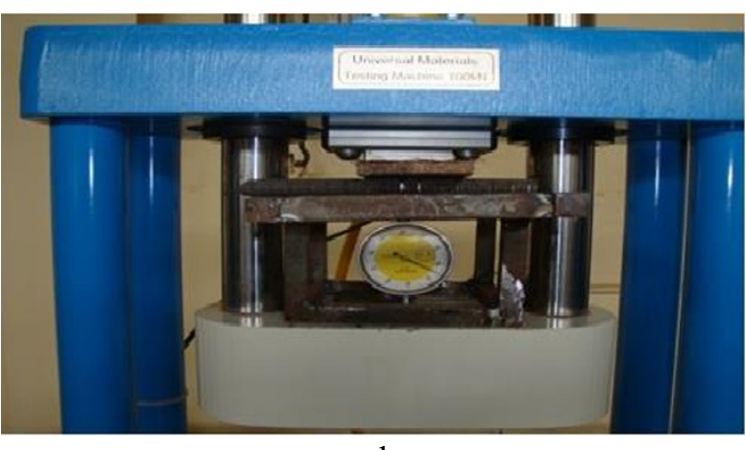

b

Figure 2 Setups for some mechanical tests. (a) Tensile test setup and (b) Flexural test setup. 


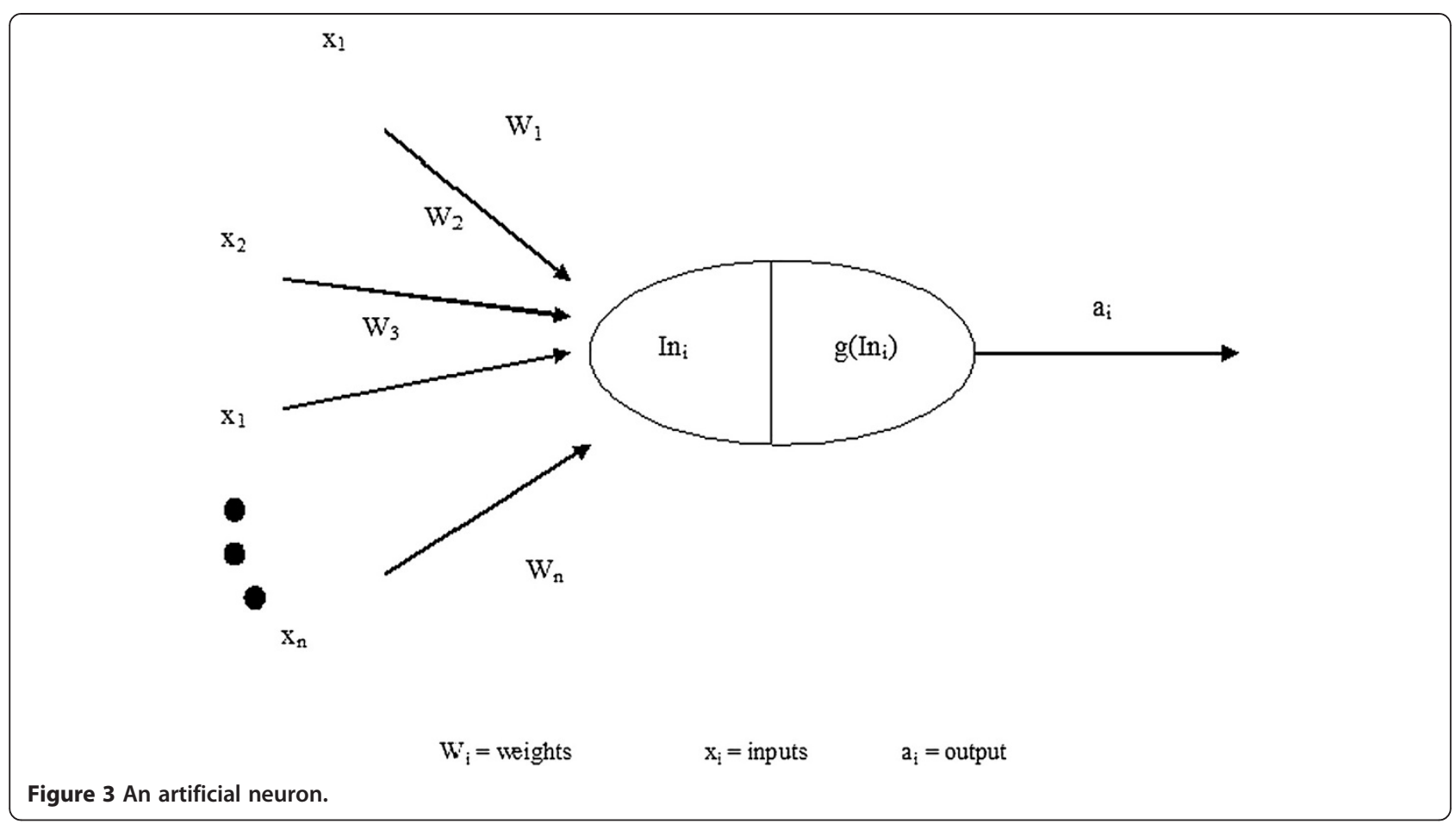

Umeonyiagu and Nwobi-Okoye 2013). One way this could be done is by developing a computational model based on artificial neural network technology for predicting the strength of polymer composite materials (Nwobi-Okoye et al. 2013; Umeonyiagu and Nwobi-Okoye 2013). With mathematical and computational models, a designer can easily find the best combination of constituent materials to balance strength and cost.

An artificial neural network (ANN), usually called 'neural network' (NN), is a mathematical model or computational model that is inspired by the structure and/or functional aspects of biological neural networks (Russell and Norvig 2003). The concept of artificial neurons was first introduced in 1943 (McCulloch and Pitts 1943). Russell and Norvig (2003) stated that since 1943 when McCulloch and Pitts introduced the concept of neurons, much more detailed and realistic models have been developed both for neurons and for larger systems in the brain, leading to the modern field of computational neuroscience. Since the work of McCulloch and Pitts in 1943, ANN has had wide application in many spheres of life. According to Maier and Dandy (2000), in recent years, ANNs have become extremely popular for prediction and forecasting in a number of areas, including finance, power generation, medicine, water resources and environmental science.

The utility of artificial neural network models lies in the fact that they can be used to infer a function from observations. This is particularly useful in applications where the complexity of the data or task makes the design of such a function by hand impractical (Russell and Norvig 2003).

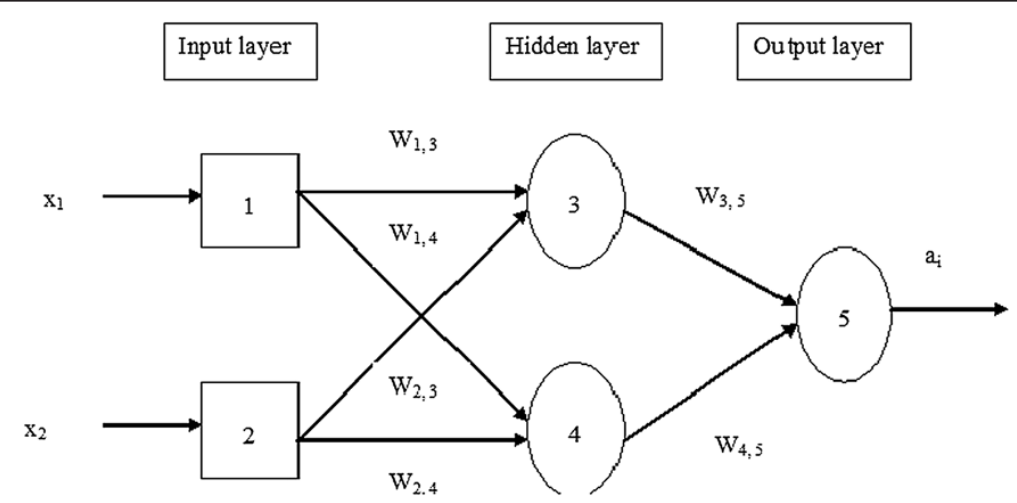

Figure 4 Two-input feedforward neural network model. 


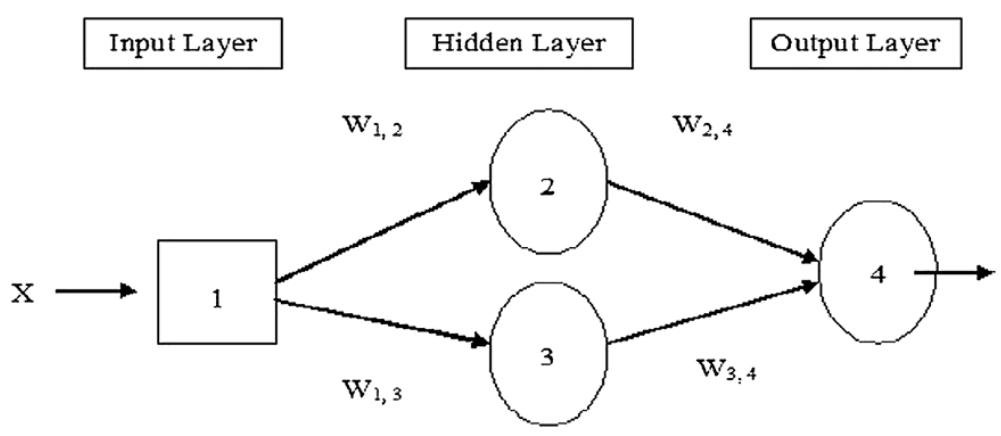

Figure 5 Single-input, three-layer feedforward neural network model.

The tasks to which artificial neural networks are applied tend to fall within the following broad categories:

i. Function approximation, or regression analysis, including time series prediction, fitness approximation and modelling

ii. Classification, including pattern and sequence recognition, novelty detection and sequential decision making

iii. Data processing, including filtering, clustering, blind source separation and compression

iv. Robotics, including directing manipulators, computer numerical control

The literature is replete with works on the application of ANNs for the prediction of properties of engineering materials. Ozerdem and Kolukisa (2009) used ANN to predict the mechanical properties of $\mathrm{Cu}-\mathrm{Sn}-\mathrm{Pb}-\mathrm{Zn}-\mathrm{Ni}$ cast alloys. In the work, $\mathrm{Cu}-\mathrm{Sn}-\mathrm{Pb}-\mathrm{Zn}-\mathrm{Ni}$ weight percent (wt\%) contents were used as inputs, while yield strength, tensile strength and elongation were the outputs. The results of the study showed that neural network was successful in the prediction of yield strength, tensile strength and elongation of $\mathrm{Cu}-\mathrm{Sn}-\mathrm{Pb}-\mathrm{Zn}-\mathrm{Ni}$ cast alloys. Hassan et al. (2009) used ANN in predicting some physical properties of (porosity and density) and hardness of aluminium-copper/silicon carbide composites. The result they obtained showed that maximum relative error for predicted values did not exceed 5.99\%. Bilim et al. (2009) used ANN to predict the compressive strength of ground granulated blast furnace slag concrete. The results showed that ANN can be an alternative approach for predicting the compressive strength of the material. Asilturk and Cunkas (2011) used artificial neural network and multiple regression method to predict the surface roughness in turning operations. The results show that ANN predicted better than the models based on regression. Mukherjee and Biswas (1997) in their paper applied artificial neural networks for the prediction of the mechanical behaviour of concrete materials at high temperature. Their results were very encouraging. Oretal and Kawashima (2003) in their paper proposed an ANN-based model to predict the confined compressive strength and corresponding strain of circular concrete columns. Their study shows the importance

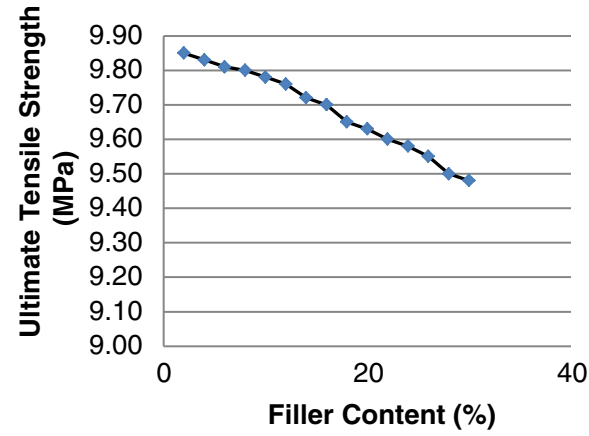

a

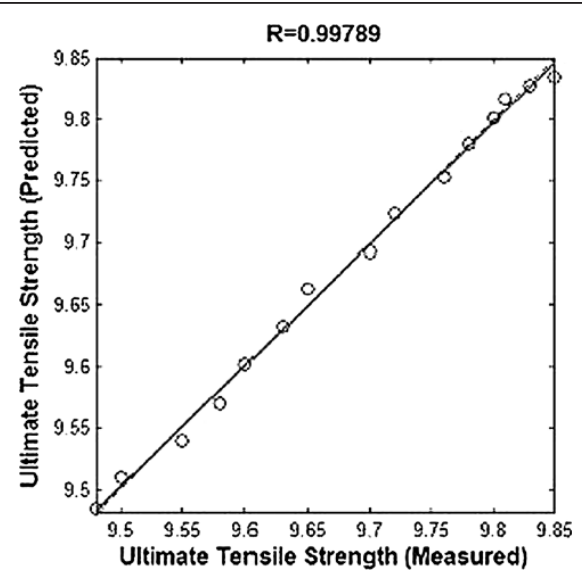

b

Figure 6 Ultimate tensile strength (experimental results and ANN predictions) at $150 \mu \mathrm{m}$ and initial LDPE UTS of 12 MPa. (a) Variation of ultimate tensile strength with filler content. (b) Prediction of ultimate tensile strength (experimental vs ANN predictions). 


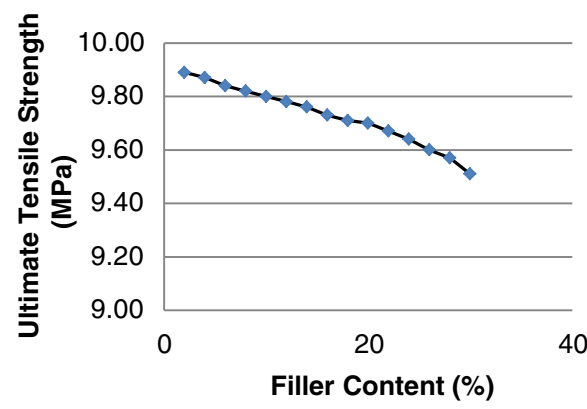

a

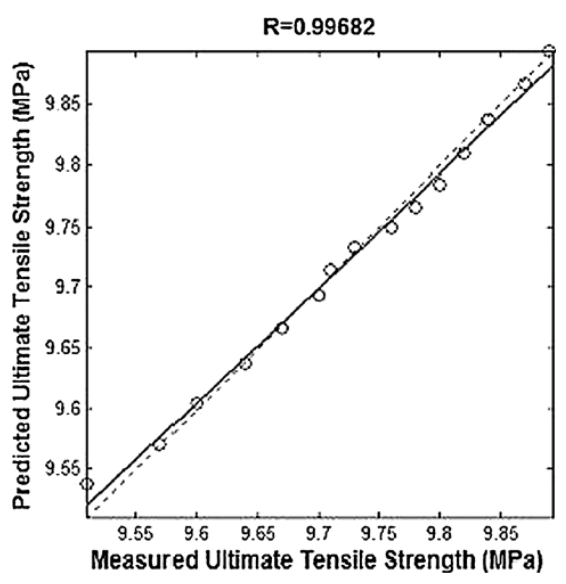

b

Figure 7 Ultimate tensile strength (experimental results and ANN predictions) at $212 \mu \mathrm{m}$ and initial LDPE UTS of 12 MPa. (a) Variation of ultimate tensile strength with filler content. (b) Prediction of ultimate tensile strength (experimental vs ANN predictions).

of validating the ANN models in simulating physical processes especially when data are limited. The ANN model they developed was also compared to some analytical models and was found to perform well. Other papers on the prediction of material strength using neural networks include the following: Lee (2003), Kasperkiewicz et al. (1995), Ahmet et al. (2006), Topcu and Saridemir (2008), etc.

Maier and Dandy (2000) reviewed 43 papers dealing with the use of neural network models for the prediction and forecasting of water resource variables in terms of the modelling process adopted. They identified inadequate model building as the obstacle militating against accurate predictions using artificial networks. They suggested that ANN models must be properly evaluated before their application in time series analysis.
Their assertion is corroborated by Chatfield (1993) when commenting on the suitability of ANNs for time series analysis and forecasting, who commented thus 'when the dust has settled, it is usually found that the new technique is neither a miraculous cure-all nor a complete disaster, but rather an addition to the analyst's toolkit which works well in some situations and not in others'.

It is important to note that a neural network modelling is purely a computational technique. Hence, if one wants to explain an underlying process or mathematical framework that produces the relationships between the dependent and independent variables, it would be better to use a more traditional statistical model like regression analysis. However, if model interpretability is not important, one can often obtain good model results more quickly using a neural network.

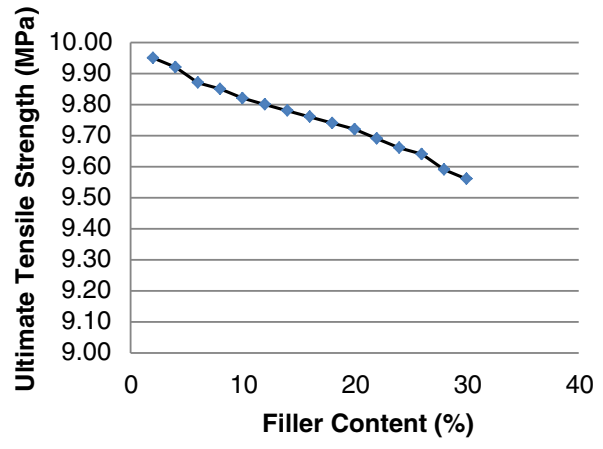

a

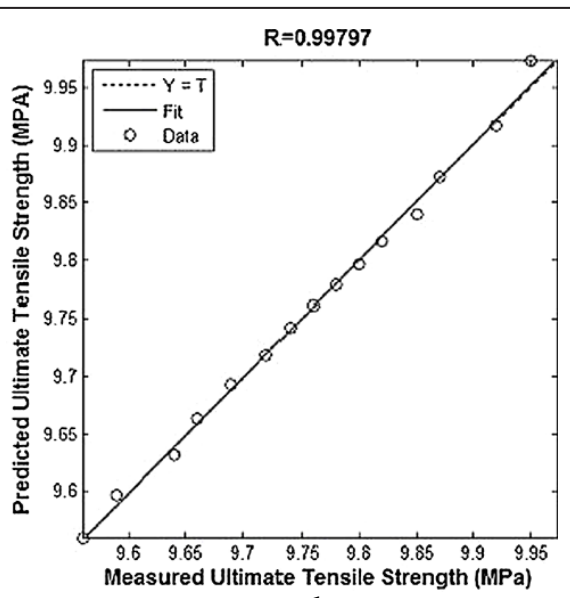

b

Figure 8 Ultimate tensile strength (experimental results and ANN predictions) at $250 \mu \mathrm{m}$ and initial LDPE UTS of 12 MPa. (a) Variation of ultimate tensile strength with filler content. (b) Prediction of ultimate tensile strength (experimental vs ANN predictions). 


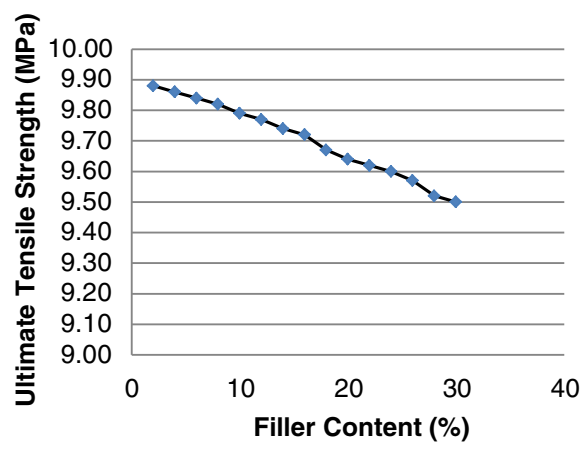

a

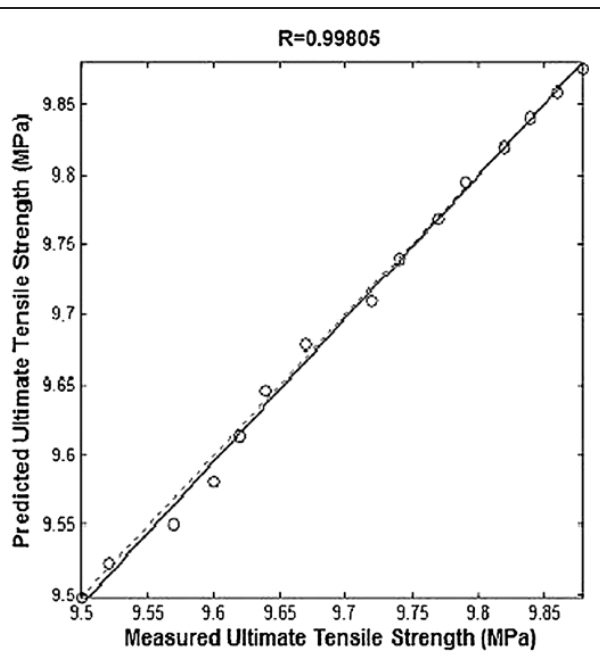

b

Figure 9 Ultimate tensile strength (experimental results and ANN predictions) at $300 \mu \mathrm{m}$ and initial LDPE UTS of 12 MPa. (a) Variation of ultimate tensile strength with filler content. (b) Prediction of ultimate tensile strength (experimental vs ANN predictions).

Reinforcement is generally responsible for strengthening the composite and improves its mechanical properties. All of the different fibres used in composites have different properties and so affect the properties of the composite in different ways. This also provides stiffness to the composites (Myers et al. 1991).

The advantages of composite materials over conventional materials stem largely from their higher specific strength, stiffness and fatigue characteristics, which enables structural design to be more versatile. They also have good resistance to corrosion, low cost, increased toughness and good resistance to fire (Bledzki and Gassan 1999).

Fillers find application in the polymer industry, almost exclusively to improve mechanical, thermal and electrical properties and dimensional stability (George et al. 2001). Fillers increase the number of chains, which share the load of a broken polymer chain.

Neural network approach was used to predict the mechanical properties of date palm wood fibre-low density polyethylene composite. Predicting mechanical properties of polymer composite is necessary in engineering design applications (Mukherjee and Biswas 1997; Lee 2003). The neural network model developed has intuitive and theoretical appeal. It was developed based on the assumption

Table 1 Ultimate tensile strength prediction summary

\begin{tabular}{llll}
\hline $\begin{array}{l}\text { Grain } \\
\text { size }(\boldsymbol{\mu m})\end{array}$ & $\begin{array}{l}\text { Correlation } \\
\text { coefficient } \boldsymbol{R}\end{array}$ & Epoch & $\begin{array}{l}\text { Mean squared } \\
\text { error (MSE) }\end{array}$ \\
\hline 150 & 0.99809 & 15 & 0.00018626 \\
212 & 0.99682 & 10 & 0.00001609 \\
250 & 0.99797 & 12 & 0.00005755 \\
300 & 0.99805 & 32 & 0.00001106 \\
\hline
\end{tabular}

that the experimental results were generated by a stochastic process. The model developed was in very good agreement with values obtained from the experiment.

Summarizing, in this work, low-density polyethylene from containers used to bag potable water was gathered, recycled and combined with date palm wood fibre flour to produce a composite material. The mechanical properties of the material, namely the ultimate tensile strength, elongation, tensile modulus, flexural strength, flexural modulus and hardness, were experimentally determined for various percentage weight compositions of date palm wood fibre ranging from $0 \%$ to $30 \%$ and for various particle sizes, namely 150, 212, 250 and $300 \mu \mathrm{m}$. Later, the experimentally determined mechanical properties of the composite at various percentage compositions of the date palm wood fibre and at various particle sizes were used to train an ANN; the trained ANN was later used to predict the mechanical properties of the composite at various percentage compositions of the date palm wood fibre and at various particle sizes.

\section{Methods}

The mechanical properties of the composite were first determined experimentally. The experimental results were subsequently used as input data to train and test the neural network model developed in this study. The procedures and materials used to obtain the experimental data are presented in this section.

\section{Materials and equipment Collection and preparation of date palm wood flour/LDPE composite}

The date palm wood was obtained from Nnamdi Azikiwe University Awka, permanent site, Anambra State, Nigeria. 


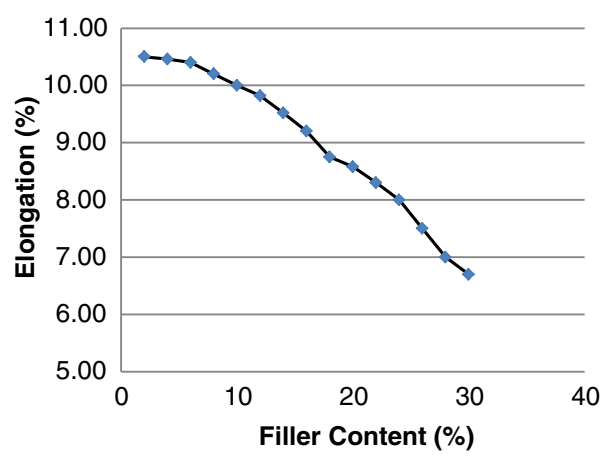

a

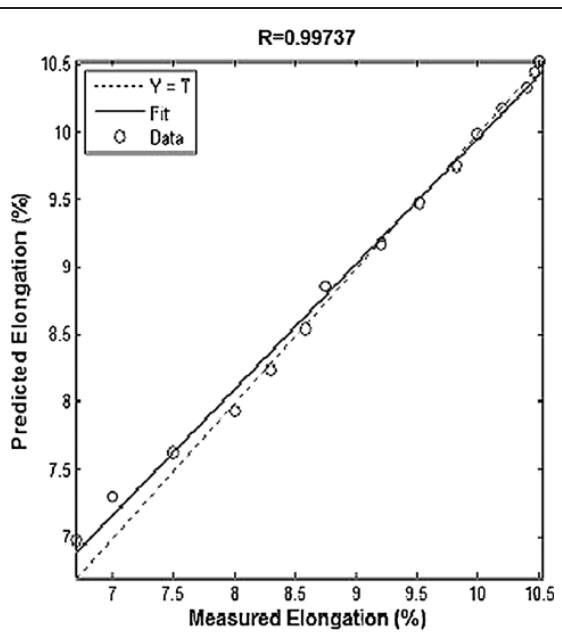

b

Figure 10 Elongation (experimental results and ANN predictions) at $150 \mu \mathrm{m}$ and initial LDPE elongation of $\mathbf{9 0 \%}$. (a) Variation of elongation with filler content. (b) Prediction of elongation (experimental vs ANN predictions).

The shells were sun-dried in the open air to a moisture content of about $8 \%$, crushed and ground. The ground wood was sieved using a mechanical sieve of size 150, 212, 250 and $300 \mu \mathrm{m}$. The date palm wood flour is shown in Figure 1. The sieved wood was dried in a laboratory oven at $105^{\circ} \mathrm{C}$ to a final moisture content of $3 \%$ to $4 \%$ and stored in plastic bags for further compounding.

Collection and preparation of recycled low-density polyethylene The recycled low-density polyethylene (LDPE) plastic container was obtained from the refuse bin. The plastic was washed and sun-dried to remove dirt. The (LDPE) materials were cut to small sizes to enable the crushing machine to accept the material after drying.

\section{Methodology}

The date palm wood flour constitutes the filler for the composite. The date palm wood flour of different weight percent was filled with the remaining percentage being LDPE. The particle sizes of 150, 212, 250 and $300 \mu \mathrm{m}$ were used to examine the size effect of date palm wood flour as filler in the properties of LDPE, respectively. These particle sizes were examined to find the one which gives the best properties on the LDPE. The date palm wood of each of the flours was filled at $2 \%, 4 \%, 6 \%, 8 \%$, $10 \%, 12 \%, 14 \%, 16 \%, 18 \%, 20 \%, 22 \%, 24 \%, 26 \%, 28 \%$ and $30 \%$ by weight of the filler content, respectively.

The filler and polyethylene were mixed at different percentage compositions of the flour. The density of

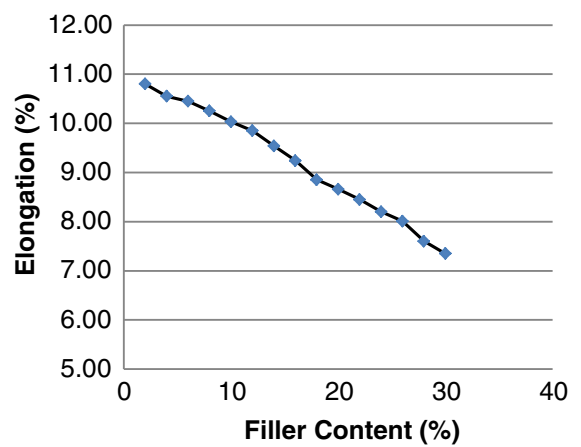

a

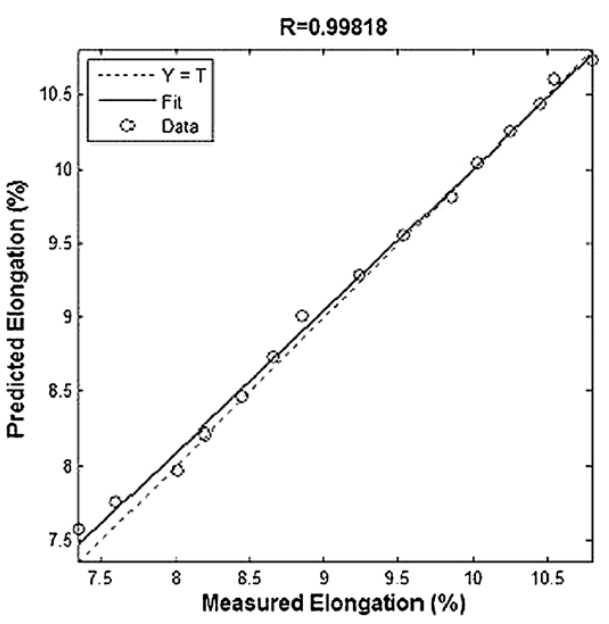

b

Figure 11 Elongation (experimental results and ANN predictions) at $212 \mu \mathrm{m}$ and initial LDPE elongation of $90 \%$. (a) Variation of elongation with filler content. (b) Prediction of elongation (experimental vs ANN predictions). 


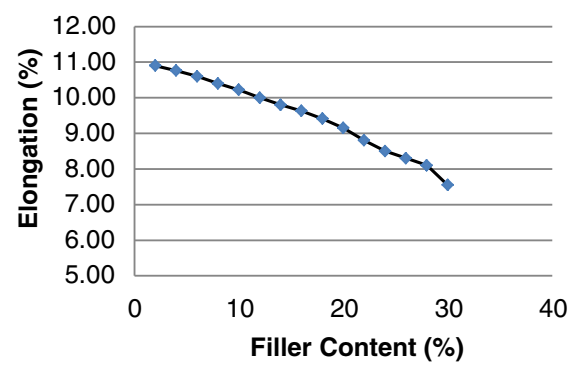

a

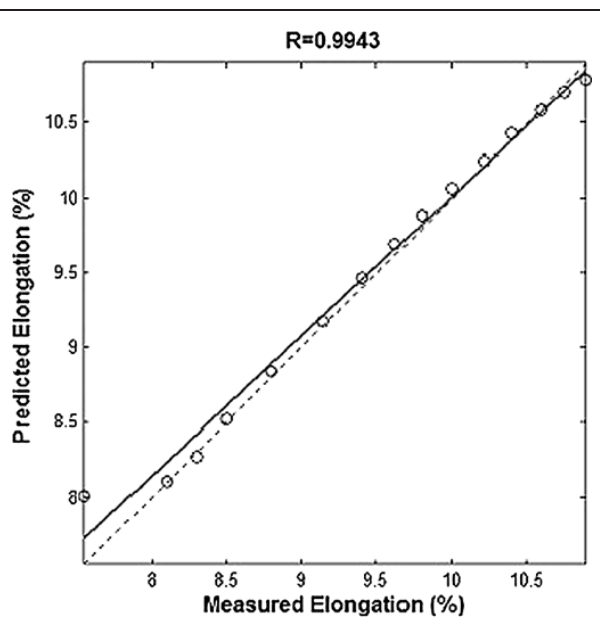

b

Figure 12 Elongation (experimental results and ANN predictions) at $250 \mu \mathrm{m}$ and initial LDPE elongation of $\mathbf{9 0 \%}$. (a) Variation of elongation with filler content. (b) Prediction of elongation (experimental vs ANN predictions).

the LDPE was $0.91 \mathrm{~g} / \mathrm{cm}^{3}$. The mixing of the recycled LDPE and date palm wood flour was done using a single screw extruder with serial number 811613 manufactured by Dongyang Fuqiang Electrical Industry Co., Ltd, China. The diameter of the screw was $25 \mathrm{~mm}$, and the ratio of length to diameter was 3.6. Since the melting point of LDPE is $115^{\circ} \mathrm{C}$, the temperature of the screw extruder was set at $130^{\circ} \mathrm{C}$ to $140^{\circ} \mathrm{C}$ during the compounding process to ensure that the melt flow index of at least $9.0 \mathrm{~g} / 10 \mathrm{~min}$ is achieved for successful mixing. Melt compounding was chosen because dry blending of the material before loading the mould could result in an uneven mix due to the considerable differences in particle size, morphology and specific gravity of the two materials. Each of the mixture was injection-moulded using an injection moulding machine. The composites which were produced were allowed to cool at room temperature. Prior to mechanical tests, the composites were conditioned at $65 \%$ relative humidity and at room temperature of $23^{\circ} \mathrm{C}$.

\section{Testing of tensile specimen properties}

The tensile test was carried out using a universal tensile machine (ENERPAC model No PUJ1200E) in accordance with ASTM D638 (ASTM 2013a). The test was performed at a cross-head speed of $5 \mathrm{~mm} / \mathrm{min}$.

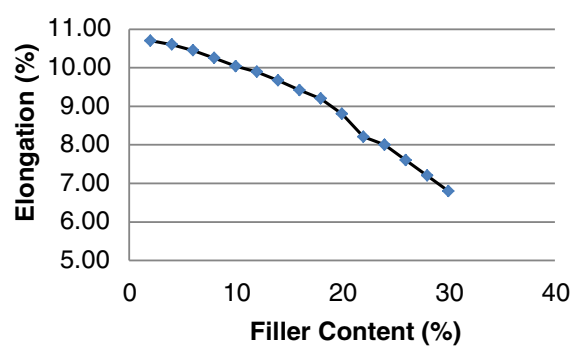

a

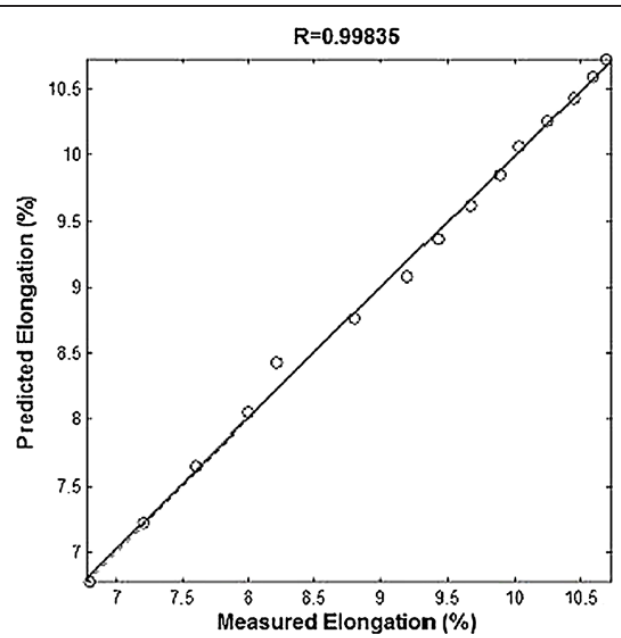

b

Figure 13 Elongation (experimental results and ANN predictions) at $300 \mu \mathrm{m}$ and initial LDPE elongation of $\mathbf{9 0 \%}$. (a) Variation of elongation with filler content. (b) Prediction of elongation (experimental vs ANN predictions). 
Table 2 Elongation prediction summary

\begin{tabular}{llll}
\hline $\begin{array}{l}\text { Grain } \\
\text { size }(\boldsymbol{\mu m})\end{array}$ & $\begin{array}{l}\text { Correlation } \\
\text { coefficient } \boldsymbol{R}\end{array}$ & Epoch & $\begin{array}{l}\text { Mean squared } \\
\text { error (MSE) }\end{array}$ \\
\hline 150 & 0.99737 & 10 & 0.00217180 \\
212 & 0.99818 & 11 & 0.00122960 \\
250 & 0.99430 & 9 & 0.00659740 \\
300 & 0.99835 & 19 & 0.00310500 \\
\hline
\end{tabular}

The dimensions of tensile test specimen size for ASTM used were $3 \mathrm{~mm} \times 12.5 \mathrm{~mm} \times 60 \mathrm{~mm}$. The specimen was placed in the grips of the machine and pulled until there was failure. The ultimate tensile strength, elongation and modulus were determined. Figure 2a shows the setup for the tensile test.

\section{Testing of flexural specimen properties}

The equipment used for this was a universal testing machine, ENERPAC model No PUJ1200E, located at Standard Organization of Nigeria, Enugu State. The test was performed under the room temperature.

The dimension of flexural test specimen size for ASTM D790 (ASTM 2013b) used was $3 \mathrm{~mm} \times 40 \mathrm{~mm} \times 140 \mathrm{~mm}$. The length of support span was $100 \mathrm{~mm}$, the specimen lied on a support span, and the load was supplied to centre of the sample. The test was stopped when failure occurred. The flexural strength and modulus were determined. Figure $2 \mathrm{~b}$ shows the setup for the flexural test.

\section{Testing of Izod notch impact specimen}

The equipment used for this test was an impact tester machine manufactured by Samuel Devison Ltd, Leeds,
England (model number LS102 DE) located at Standard Organization of Nigeria, Enugu State.

The dimension of Izod impact testing specimen size for ASTM D256 (ASTM 2013c) used was $3 \mathrm{~mm} \times 10 \mathrm{~mm} \times$ $55 \mathrm{~mm}$. The specimen was clamped into the machine. The pendulum from the impact tester was released and allowed to strike through the specimen. The Izod notched impact energy absorbed was determined.

\section{Neural networks}

As has been previously mentioned, the origin of artificial neurons (ANNs) is based on the work of McCulloch and Pitts in 1943 (McCulloch and Pitts 1943). Artificial neurons are building blocks for artificial neural networks. We shall discuss here the structure artificial neurons and neural network used in this research.

\section{Artificial neurons}

Artificial neural networks make use of artificial neurons. ANNs simulate the manner of operation of natural neurons in the human body. The basic unit of operation of an ANN is the neuron shown in Figure 3.

In a typical neuron shown in Figure 3, the input to the neuron $x_{i}$ is multiplied by a weighting function $W_{i}$ to generate the transformed input $W_{i} x_{i}$. The transformed inputs are summed to obtain the summed input. The summed input constitutes the variables to the activation/transfer function, $g$, which generates the output $a_{i}$. The output of the transfer function is compared to a threshold value. If the output is greater than the threshold value, the neuron is activated and signal is transferred to the neuron output; alternatively, if it is less, the signal is blocked.

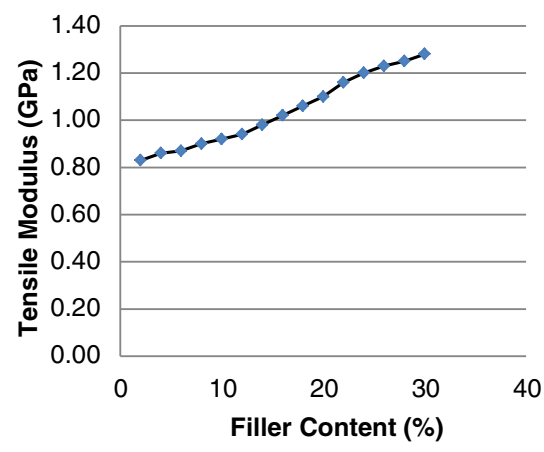

a

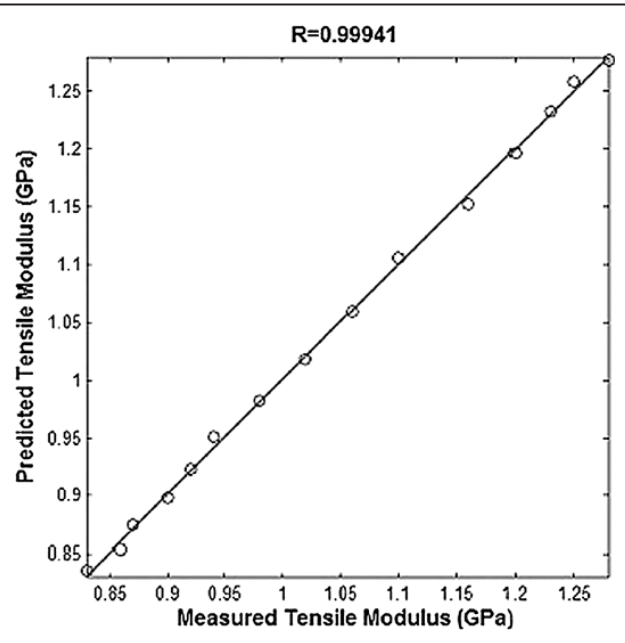

b

Figure 14 Tensile modulus (experimental results and ANN predictions) at $150 \mu \mathrm{m}$ and initial LDPE modulus of $0.4 \mathrm{GPa}$. (a) Variation of tensile modulus with filler content. (b) Prediction of tensile modulus (experimental vs ANN predictions). 


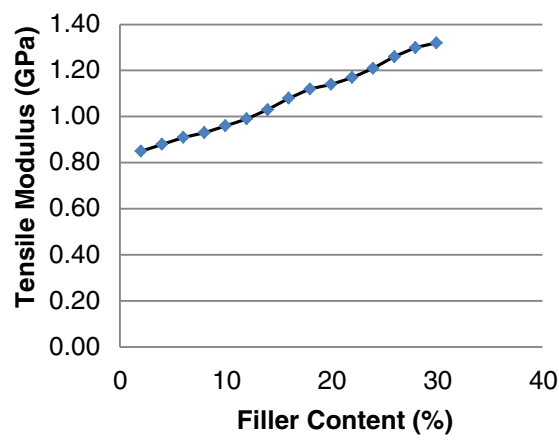

a

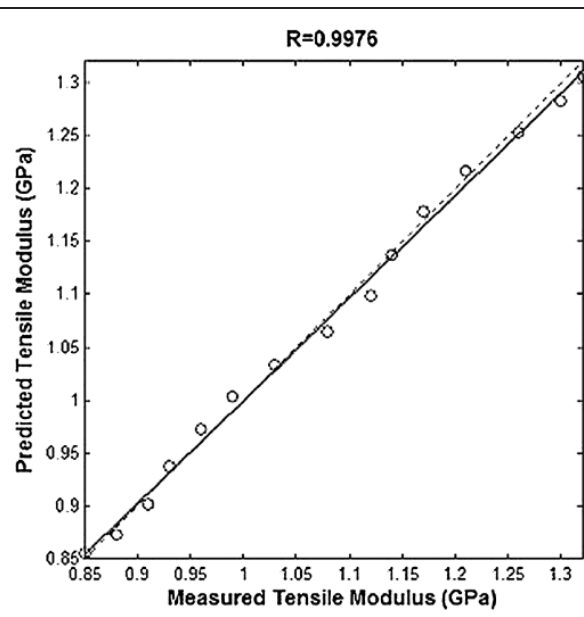

$\mathrm{b}$

Figure 15 Tensile modulus (experimental results and ANN predictions) at $212 \mu \mathrm{m}$ and initial LDPE modulus of $0.4 \mathrm{GPa}$. (a) Variation of tensile modulus with filler content. (b) Prediction of tensile modulus (experimental vs ANN predictions).

Given an input vector $X=\left(x_{1}, x_{2}, \ldots x_{n}\right)$, the activations of the input units are set to $\left(a_{1}, a_{2}, \ldots a_{n}\right)=\left(x_{1}, x_{2}, \ldots x_{n}\right)$ and the network computes to

$$
\begin{aligned}
& I n_{i}=\sum_{j=1}^{n} W_{j, i} a_{j} \\
& a_{i}=g\left(\operatorname{In}_{i}\right) .
\end{aligned}
$$

The transfer function could be a threshold transfer function, a sin function, a sigmoid function, hyperbolic tangent function, etc. Differentiable transfer functions are preferred. Similarly, non-linear transfer functions perform better than linear transfer function. Bearing these in mind, in this particular application, we chose the sigmoid function. The sigmoid activation function is given by the equation

$$
a_{i}=g\left(I n_{i}\right)=\frac{1}{1-e^{-I n_{i}}} .
$$

Training the network (learning) could be a supervised or unsupervised training. In supervised training, the network is provided with the inputs and appropriate outputs; hence, the network is trained with a set of examples in a specified manner. In unsupervised/adaptive learning, the network is provided with inputs but not the outputs. In this present application, we used the

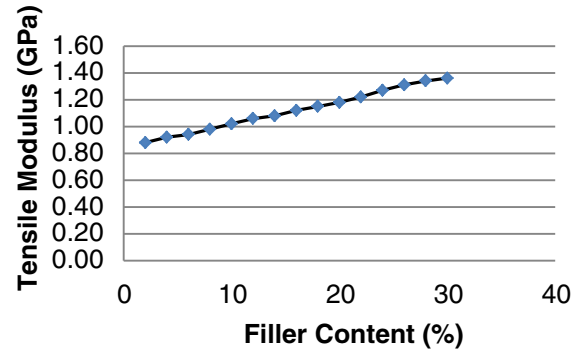

a

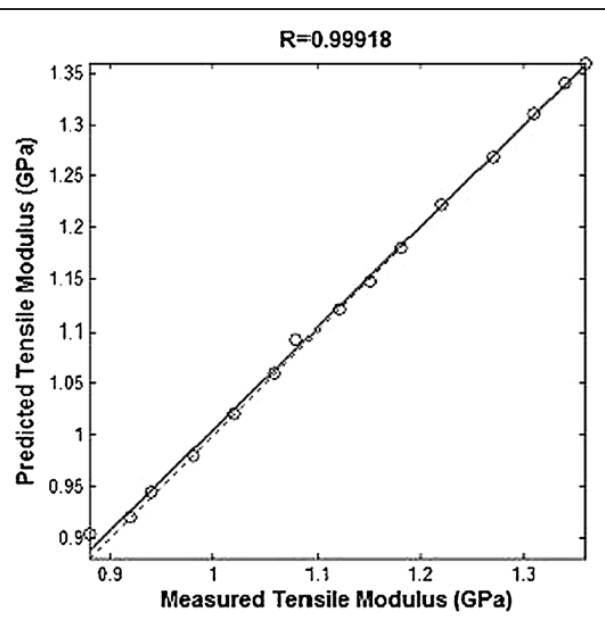

b

Figure 16 Tensile modulus (experimental results and ANN predictions) at $250 \mu \mathrm{m}$ and initial LDPE modulus of $0.4 \mathrm{GPa}$. (a) Variation of tensile modulus with filler content. (b) Prediction of tensile modulus (experimental vs ANN predictions). 


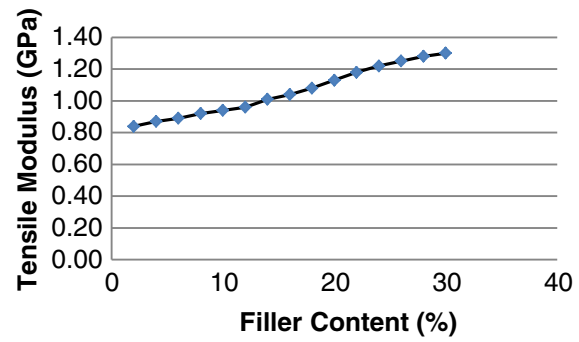

a

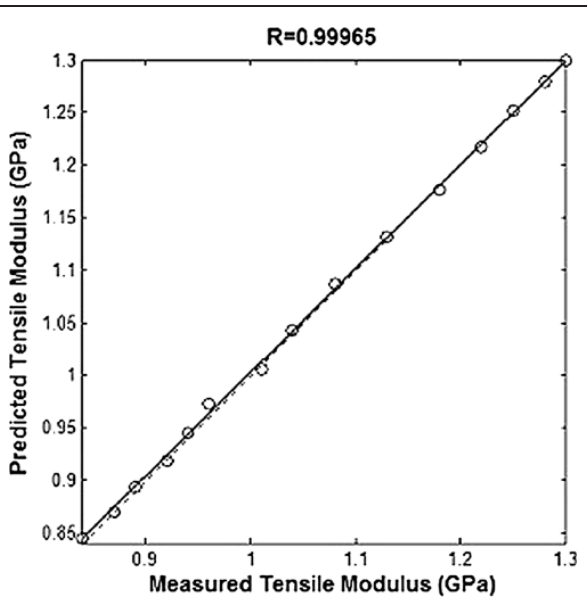

b

Figure 17 Tensile modulus (experimental results and ANN predictions) at $300 \mu \mathrm{m}$ and initial LDPE modulus of $0.4 \mathrm{GPa}$. (a) Variation of tensile modulus with filler content. (b) Prediction of tensile modulus (experimental vs ANN predictions).

supervised learning; hence, the appropriate network architecture is the feedforward architecture.

\section{The feedforward network architecture}

As has been mentioned, the developed neural network models are feedforward multiplayer perceptron networks (MLP). The hidden units as previously noted use the sigmoid activation function. The network model is shown in Figure 4.

In the feedforward network shown in Figure 4, the output of the network is compared with the desired output. The difference between the output and the desired output is known as the error, $E$. ANNs learn by trying to minimize this error. The learning process uses optimisation algorithms such as the Levenberg-Marquardt algorithm, gradient descent algorithm, genetic algorithm or some other natural optimisation algorithm. These algorithms work by adjusting the weights, $W_{i}$, such that the error, $E$, is minimized. Most ANNs use the simple gradient descent optimisation algorithm. In this work, we used this algorithm. Hence, the learning process uses the sum of squares error criterion $E$ to measure the effectiveness of the learning algorithm.

$$
E=\frac{1}{2} \operatorname{Err}^{2} \equiv \frac{1}{2}\left(y-h_{W}(x)\right)^{2}
$$

Table 3 Tensile modulus prediction summary

\begin{tabular}{llll}
\hline Grain size $(\boldsymbol{\mu m})$ & $\begin{array}{l}\text { Correlation } \\
\text { coefficient } \boldsymbol{R}\end{array}$ & Epoch & $\begin{array}{l}\text { Mean squared } \\
\text { error (MSE) }\end{array}$ \\
\hline 150 & 0.99737 & 11 & 0.00004180 \\
212 & 0.99760 & 10 & 0.00016772 \\
250 & 0.99918 & 7 & 0.00031089 \\
300 & 0.99965 & 12 & 0.00000615 \\
\hline
\end{tabular}

Here

$y=Y=$ the true/experimental value

$$
\hat{Y}=h_{W}(x)
$$

${ }^{\boldsymbol{h}} \boldsymbol{W}^{(\mathbf{x})}$ is the output of the perceptron.

The ANN for predicting the mechanical properties of date palm fibre/polymer composite

Recall that our application is for the prediction of the mechanical properties of polymer composite, and we used supervised learning. Hence, $70 \%$ of the data was used for training, while $30 \%$ was used for testing and validation. The maximum number of epoch was set to 1,000 . The epoch was set to 1,000 not for any theoretical reasons but to ensure that there is sufficient number of iterations during the learning process. Also, learning was fast at this level, and the optimum performance was obtained in all cases when the epoch was less than 50. The ANN training was done using the Levenberg-Marquardt algorithm which performed better than others.

Single network architecture was used in the study. The network architecture consists of a single input unit, one hidden layer with two hidden units (nodes) and one output unit. We used the sigmoid transfer function in the all the processing units in the hidden layer. The network structure is shown in Figure 5. The input $X$ to the neural network is the filler content in percent.

The network design was based on the fact that a typical back-propagation network has an input layer, an output layer, and at least one hidden layer (Anderson and McNeill 1992). There is no theoretical limit on the number of hidden layers, but typically there is just one or two (Anderson and McNeill 1992). Some work has 


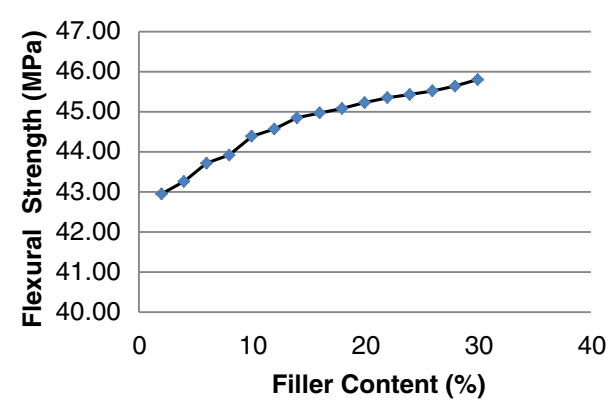

a

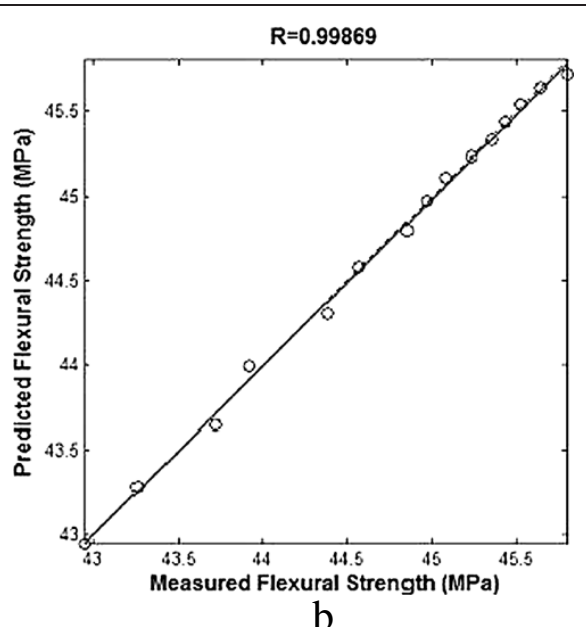

Figure 18 Flexural strength (experimental results and ANN predictions) at $150 \mu \mathrm{m}$ and initial LDPE strength of $40 \mathrm{MPa}$. (a) Variation of flexural strength with filler content. (b) Prediction of flexural strength (experimental vs ANN predictions).

been done which indicates that a maximum of four layers (three hidden layers and one output layer) are required to solve problems of any complexity (Anderson and McNeill 1992). According to one of the rules of designing typical back-propagation networks, if the process being modelled is separable into multiple stages, then additional hidden layer(s) may be required (Anderson and McNeill 1992). Bearing these in mind, we limited the number of hidden layers in our network to one.

The input-output relationship being modelled is univariate which is quite simple, unlike complex multivariate relationships. Anderson and McNeill (1992) stated that one of the rules of designing typical backpropagation networks is that as the complexity in the relationship between the input data and the desired output increases, the number of the processing elements in the hidden layer should increase. Based on the rule for determining the upper bound of processing elements in the hidden layer (Anderson and McNeill 1992), we chose a scaling factor of 2 . This choice is based on the fact that our training data is not noisy with an exact relationship of the input to the output. Consequently, we determined the upper bound of the processing units in the hidden layer to be three. Hence, in accordance with this rule, we chose two processing elements in our hidden layer instead of three or more. Moreover, when we increased the processing elements to more than two, we did not obtain any improvement in our results. Also, when the number of elements was reduced to one, the results obtained were poorer than when the elements were two. Hence, for better efficiency and model parsimony, we stuck to two processing elements.

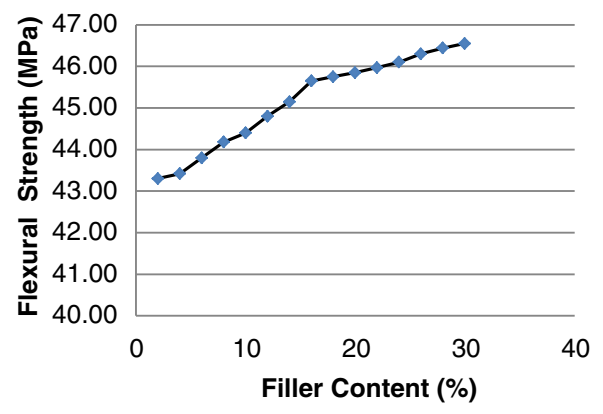

a

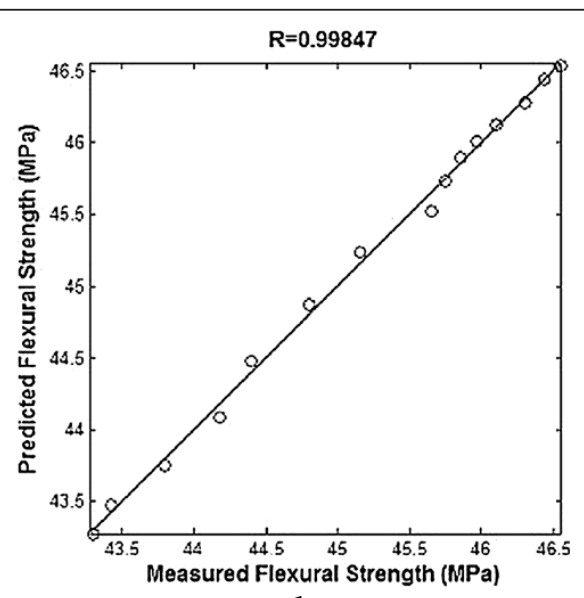

$\mathrm{b}$

Figure 19 Flexural strength (experimental results and ANN predictions) at $212 \mu \mathrm{m}$ and initial LDPE strength of $40 \mathrm{MPa}$. (a) Variation of flexural strength with filler content. (b) Prediction of flexural strength (experimental vs ANN predictions). 


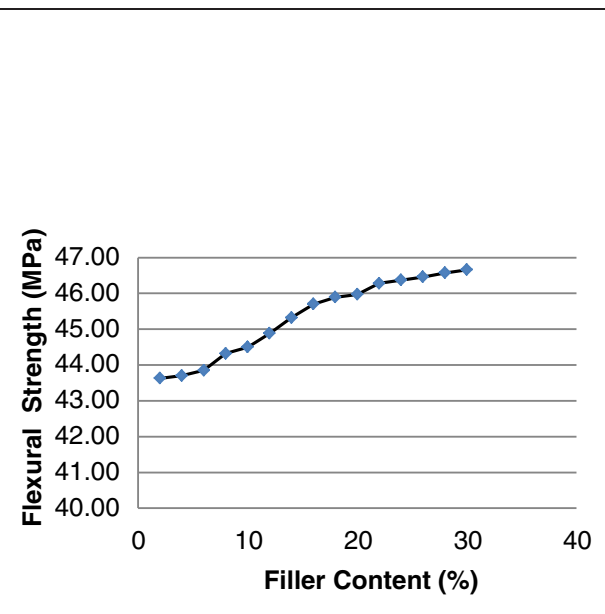

a

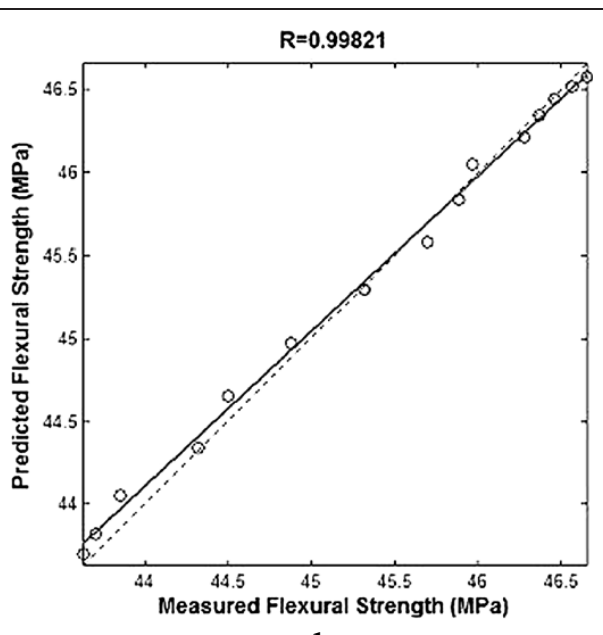

b

Figure 20 Flexural strength (experimental results and ANN predictions) at $250 \mu \mathrm{m}$ and initial LDPE strength of $40 \mathrm{MPa}$. (a) Variation of flexural strength with filler content. (b) Prediction of flexural strength (experimental vs ANN predictions).

\section{Results and discussion}

Prediction of the effect of filler content on the ultimate tensile strength

Figures $6 a, 7 a, 8 a$ and 9a show the effect of filler content on the ultimate tensile strength (UTS) of date palm wood flour/LDPE composite at 150-, 212-, 250- and 300- $\mu \mathrm{m}$ particle sizes and initial LDPE ultimate tensile strength of $12 \mathrm{MPa}$. As shown in the figures, increase in filler content decreased the ultimate tensile strength. This trend was equally observed in oil palm filled with polypropylene by Zaini et al. (1995). This trend was due to weak chemical interaction between the filler and LDPE phase (Felix and Gatenholm 1991). When the particle size was $150 \mu \mathrm{m}$, as the filler content increased from $2 \%$ to $30 \%$, the ultimate tensile strength of date palm wood flour/LDPE composite decreased from 9.85 to 9.48 $\mathrm{MPa}$.

At $212 \mu \mathrm{m}$, the tensile strength of date palm wood flour/LDPE composite decreased from 9.89 to 9.51 MPa. At $250 \mu \mathrm{m}$, it decreased from 9.95 to $9.56 \mathrm{MPa}$. At $300 \mu \mathrm{m}$, it decreased from 9.88 to $9.50 \mathrm{MPa}$. The slight decrease in ultimate tensile strength in the entire composite may be due to increase in interfacial area as a result of addition of hydrophilic filler to hydrophobic matrix which worsened the interfacial bonding between them thereby decreasing the tensile strength. Generally, the tensile strength of the composites decreased with increasing filler loading due to the poor interfacial bonding between the filler and the matrix polymer. The poor bonding causes increased micro voids in the composites.

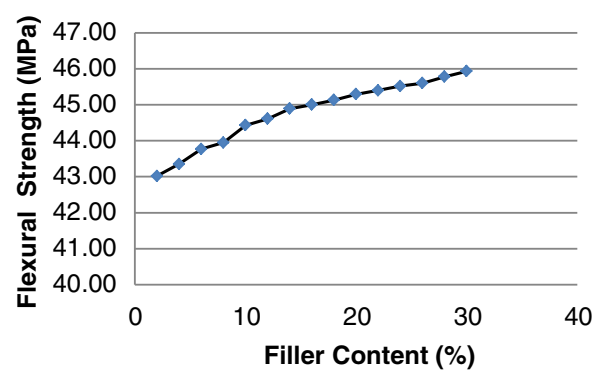

a

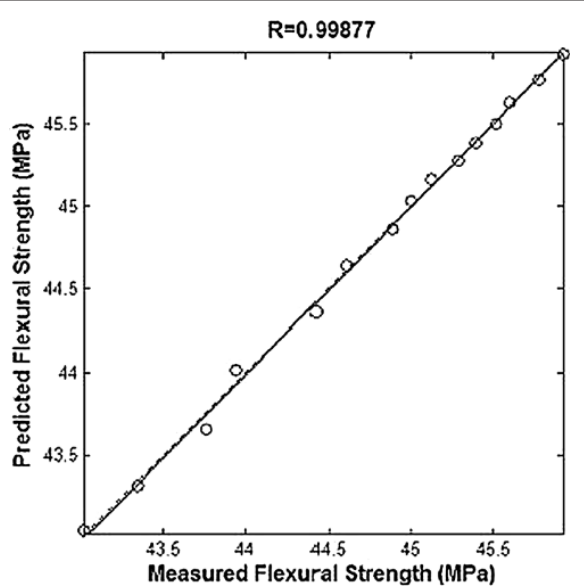

b

Figure 21 Flexural strength (experimental results and ANN predictions) at $\mathbf{3 0 0} \mu \mathrm{m}$ and initial LDPE strength of 40 MPa. (a) Variation of flexural strength with filler content. (b) Prediction of flexural strength (experimental vs ANN predictions). 
Table 4 Flexural strength prediction error summary

\begin{tabular}{llll}
\hline Grain size $(\boldsymbol{\mu m})$ & $\begin{array}{l}\text { Correlation } \\
\text { coefficient } \boldsymbol{R}\end{array}$ & Epoch & $\begin{array}{l}\text { Mean squared } \\
\text { error (MSE) }\end{array}$ \\
\hline 150 & 0.99869 & 14 & 0.00359860 \\
212 & 0.99847 & 23 & 0.00322870 \\
250 & 0.99821 & 10 & 0.00311260 \\
300 & 0.99877 & 73 & 0.00055418 \\
\hline
\end{tabular}

The observation is in line with that of Yang et al. (2006) in LDPE-wood flour system.

Figures $6 \mathrm{~b}, 7 \mathrm{~b}, 8 \mathrm{~b}$ and $9 \mathrm{~b}$ show the artificial neural network predictions of the ultimate tensile strength of date palm wood fibre/LDPE composite for grain sizes of $150,212,250$ and $300 \mu \mathrm{m}$. As the figures show, there is very good agreement with the artificial neural network predictions and experimental results with the correlation coefficients greater than 0.99 .

Table 1 shows the ANN prediction summary for ultimate tensile strength. As shown in the table, the maximum correlation coefficient is 0.99809 , while the minimum correlation coefficient is 0.99682 . Hence, the ANN predictions are very good.

Prediction of the effect of filler content on the elongation Figures 10a, 11a, 12a and 13a show the effect of filler content on the elongation of date palm wood flour/LDPE composite at 150-, 212-, 250- and 300- $\mu$ m particle sizes and initial LDPE of $90 \%$. As shown in the figures, increase in the filler content decreased the elongation. This trend was due to low interfacial adhesion between the thermoplastic layer and the filler (Bledzki and Gassan 1999). Similar trends were exhibited for wood flour-filled polypropylene composites (Berger and Stark 1997).
When the filler content increased from $2 \%$ to $30 \%$ at a particle size of $150 \mu \mathrm{m}$, the elongation of date palm wood flour/LDPE composite decreased from $10.50 \%$ to $6.70 \%$. At $212 \mu \mathrm{m}$, it decreased from $10.80 \%$ to $7.35 \%$. At $250 \mu \mathrm{m}$, it decreased from $10.90 \%$ to $7.55 \%$. At $300 \mu \mathrm{m}$, it decreased from $10.70 \%$ to $6.80 \%$.

Figures 10b, 11b, 12b and 13b show the artificial neural network predictions of the elongation of date palm wood fibre/LDPE composite for grain sizes of 150, 212, 250 and $300 \mu \mathrm{m}$. As the figures show, with the correlation coefficients greater than 0.99 , there is very good agreement with the artificial neural network predictions and experimental results.

Table 2 shows the ANN prediction summary for elongation. As shown in the table, the maximum correlation coefficient is 0.99835 , while the minimum is 0.99430 . Hence, the ANN predictions are very good.

\section{Prediction of the effect of filler content on the tensile modulus}

Figures 14a, 15a, 16a and 17a show the effect of filler content on the tensile modulus of date palm wood flour/LDPE composite at 150-, 212-, 250- and 300- $\mu \mathrm{m}$ particle sizes and initial LDPE of 0.4 GPa. As shown in the figures, increase in the filler content increased the tensile modulus. This trend was due to stiffness of the reinforcement which increases with increase in filler content (Zaini et al. 1995).

When filler content increased from $2 \%$ to $30 \%$, at $150 \mu \mathrm{m}$, the tensile modulus of date palm wood flour composite increased from 0.83 to $1.28 \mathrm{GPa}$. At $212 \mu \mathrm{m}$, it increased from 0.85 to $1.32 \mathrm{GPa}$. At $250 \mu \mathrm{m}$, it increased from 0.88 to $1.36 \mathrm{GPa}$. At $300 \mu \mathrm{m}$, it increased from 0.84 to $1.30 \mathrm{GPa}$. The increase in tensile modulus could be attributed to increase in stiffness of the composite

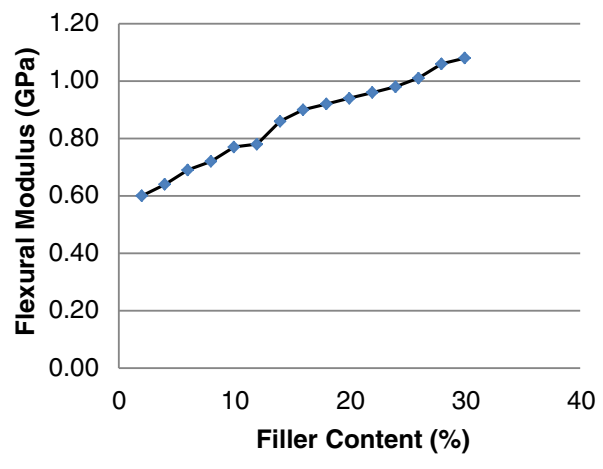

a

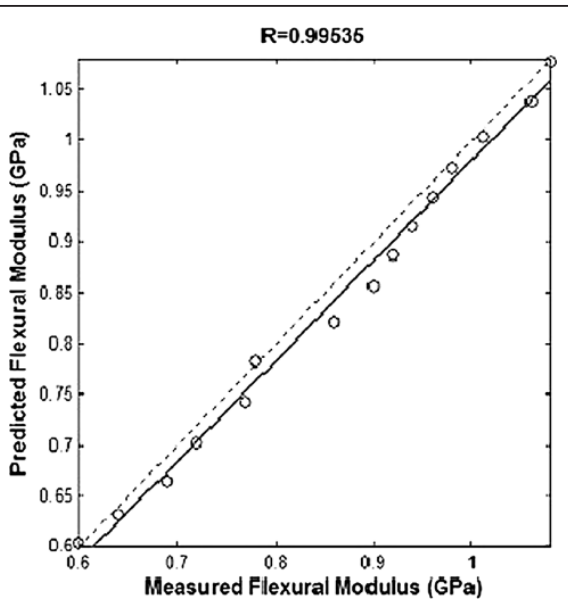

b

Figure 22 Flexural modulus (experimental results and ANN predictions) at $150 \mu \mathrm{m}$ and initial LDPE modulus of $0.25 \mathrm{GPa}$. (a) Variation of flexural modulus with filler content. (b) Prediction of flexural modulus (experimental vs ANN predictions). 


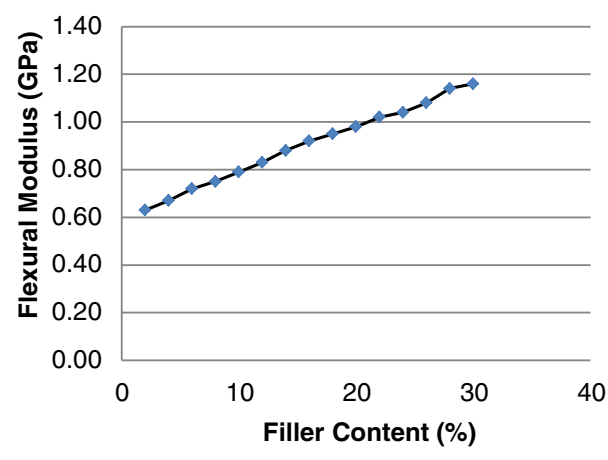

a

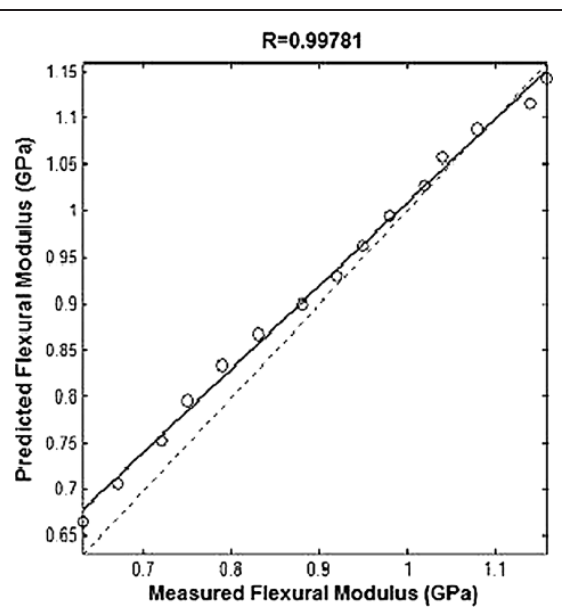

$\mathrm{b}$

Figure 23 Flexural modulus (experimental results and ANN predictions) at $212 \mu \mathrm{m}$ and initial LDPE modulus of $0.25 \mathrm{GPa}$. (a) Variation of flexural modulus with filler content. (b) Prediction of flexural modulus (experimental vs ANN predictions).

which increased with increase in filler content (Zaini et al. 1995).

Figures 14b, 15b, 16b and 17b show the artificial neural network predictions of the tensile modulus of date palm wood fibre/LDPE composite for grain sizes of 150, 212, 250 and $300 \mu \mathrm{m}$. As the figures show, with the correlation coefficients greater than 0.99 , there is very good agreement with the artificial neural network predictions and experimental results.

Table 3 shows the ANN predictions summary for tensile modulus. As shown in the table, the maximum correlation coefficient is 0.99965 , while the minimum is 0.99737 . Hence, the ANN predictions are very good.

\section{Prediction of the effect of filler content on the flexural strength}

Figures 18a, 19a, 20a and 21a show the effect of filler content on the flexural strength of date palm wood flour/LDPE composite at 150-, 212-, 250- and 300- $\mathrm{mm}$ particle sizes and initial LDPE flexural strength of $40 \mathrm{MPa}$. As shown in the figures, increase in the filler content of composite increased the flexural strength.

When filler content increased from $2 \%$ to $30 \%$ at $150 \mu \mathrm{m}$, the flexural strength of date palm wood flour/LDPE composite increased from 42.95 to $45.80 \mathrm{MPa}$. At $212 \mu \mathrm{m}$, it increased from 43.30 to $46.55 \mathrm{MPa}$. At $250 \mu \mathrm{m}$, it increased from 43.63 to $46.66 \mathrm{MPa}$. At $300 \mu \mathrm{m}$, it increased from

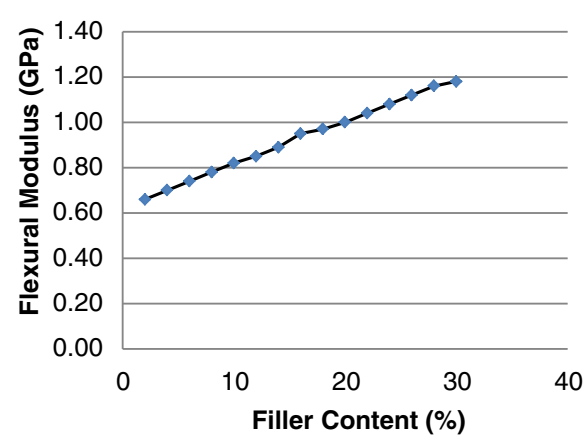

a

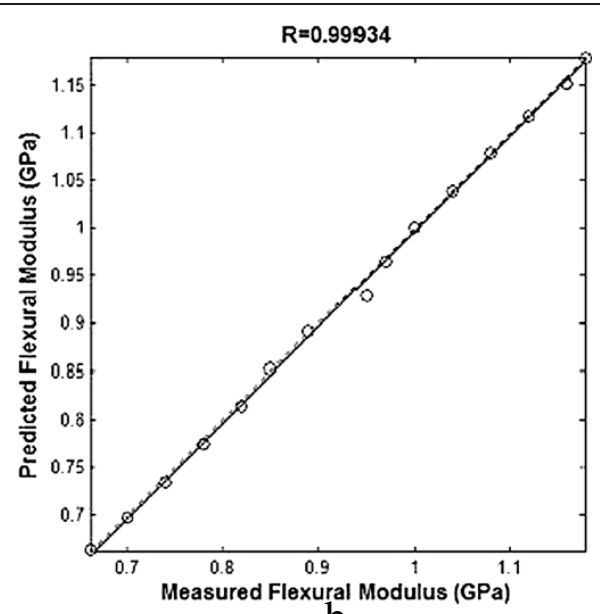

b

Figure 24 Flexural modulus (experimental results and ANN predictions) at $250 \mu \mathrm{m}$ and initial LDPE modulus of $0.25 \mathrm{GPa}$. (a) Variation of flexural modulus with filler content. (b) Prediction of flexural modulus (experimental vs ANN predictions). 


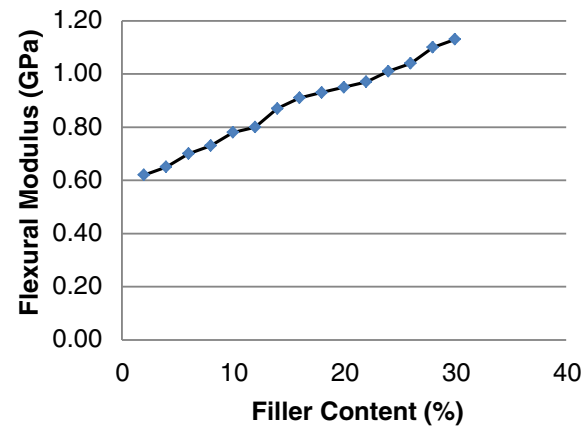

a

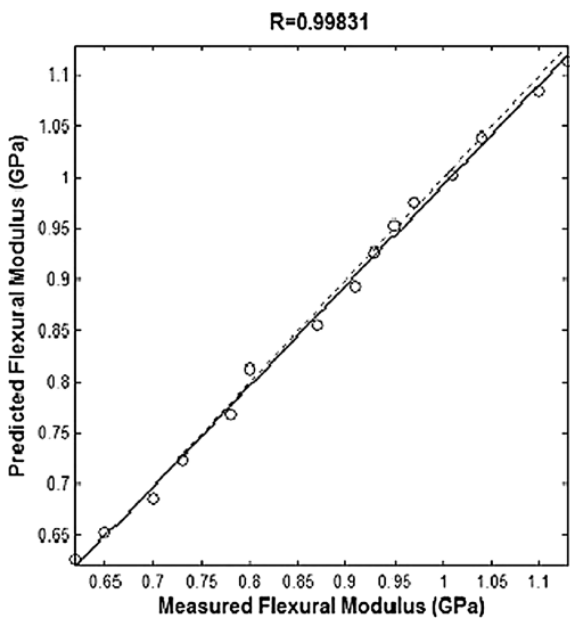

$\mathrm{b}$

Figure 25 Flexural modulus (experimental results and ANN predictions) at $300 \mu \mathrm{m}$ and initial LDPE modulus of $0.25 \mathrm{GPa}$. (a) Variation of flexural modulus with filler content. (b) Prediction of flexural modulus (experimental vs ANN predictions).

43.02 to $45.93 \mathrm{MPa}$. This trend also was observed in wood species-filled polypropylene by Brent (1996). The improvement in flexural properties could be attributed to high strength and modulus of the cellulose fibres.

Figures 18b, 19b, 20b and 21b show the artificial neural network predictions of the flexural strength of date palm wood fibre/LDPE composite for grain sizes of 150, 212, 250 and $300 \mu \mathrm{m}$. As the figures show, there is very good agreement with the artificial neural network predictions and experimental results.

Table 4 shows the ANN prediction summary for flexural strength. As shown in the table, the maximum correlation coefficient is 0.99877 , while the minimum is 0.99821 . Hence, the ANN predictions are very good.

\section{Effect of filler content on the flexural modulus}

Figures 22a, 23a, 24a and 25a show the effect of filler content on the flexural modulus of date palm wood flour/LDPE composite at 150-, 212-, 250- and 300- $\mu \mathrm{m}$ particle sizes and initial LDPE of $0.25 \mathrm{GPa}$. As shown in the figures, increase in the filler content increased the flexural modulus.

When filler content increase from $2 \%$ to $30 \%$, at $150 \mu \mathrm{m}$, the flexural modulus of date palm wood flour/LDPE composite increased from 0.6 to $1.08 \mathrm{GPa}$. At $212 \mu \mathrm{m}$,

Table 5 Flexural modulus prediction summary

\begin{tabular}{llll}
\hline Grain size $(\mu \mathrm{m})$ & $\begin{array}{l}\text { Correlation } \\
\text { coefficient } \boldsymbol{R}\end{array}$ & Epoch & $\begin{array}{l}\text { Mean squared } \\
\text { error (MSE) }\end{array}$ \\
\hline 150 & 0.99535 & 10 & 0.00096335 \\
212 & 0.99781 & 12 & 0.00035379 \\
250 & 0.99934 & 10 & 0.00002759 \\
300 & 0.99831 & 9 & 0.00014008 \\
\hline
\end{tabular}

it increased from 0.63 to $1.16 \mathrm{GPa}$. At $250 \mu \mathrm{m}$, it increased from 0.66 to $1.18 \mathrm{GPa}$. At $300 \mu \mathrm{m}$, it increased from 0.62 to $1.13 \mathrm{GPa}$. The addition of filler content to thermoplastics increased the modulus. This has been observed with oil palm wood flour-filled polypropylene by Zaini et al. (1995). The improvement in flexural modulus could be attributed to high strength and modulus of the cellulose fibres.

Figures 22b, 23b, 24b and 25b show the artificial neural network predictions of the flexural modulus of date palm wood fibre/LDPE composite for grain sizes of 150, 212, 250 and $300 \mu \mathrm{m}$. As the figures show, there is very good agreement with the artificial neural network predictions and experimental results.

Table 5 shows the ANN prediction summary for flexural modulus. As shown in the table, the maximum correlation coefficient is 0.99934, while the minimum is 0.99535 . Hence, the ANN predictions are very good.

\section{Prediction of the effect of filler content on the Izod notched impact energy}

Figures 26a, 27a, 28a and 29a show the effect of filler content on the Izod notched impact energy of groundnut shell and groundnut shell flour/LDPE composite at 150-, 212-, 250- and 300- $\mu \mathrm{m}$ particle sizes and initial LDPE of $1.1 \mathrm{~kJ} / \mathrm{m}$. As shown in the figures, increase in the filler content increased the Izod notched impact energy. This trend has similar reason with tensile modulus.

When filler content increased from $2 \%$ to $30 \%$ at $150 \mu \mathrm{m}$, the Izod notched impact energy increased from 1.45 to $1.92 \mathrm{~kJ} / \mathrm{m}$. At $212 \mu \mathrm{m}$, it increased from 1.48 to $1.97 \mathrm{~kJ} / \mathrm{m}$. At $250 \mu \mathrm{m}$, it increased from 1.51 to $2.00 \mathrm{~kJ} / \mathrm{m}$. At $300 \mu \mathrm{m}$, it increased from 1.56 to $2.06 \mathrm{~kJ} / \mathrm{m}$. As the concentration of the filler content increased, Izod notched impact energy 


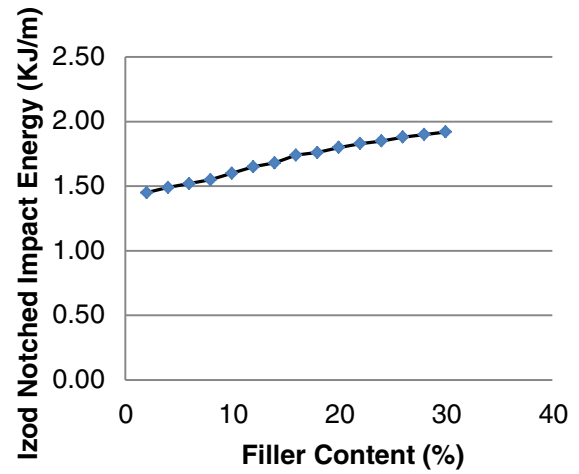

a

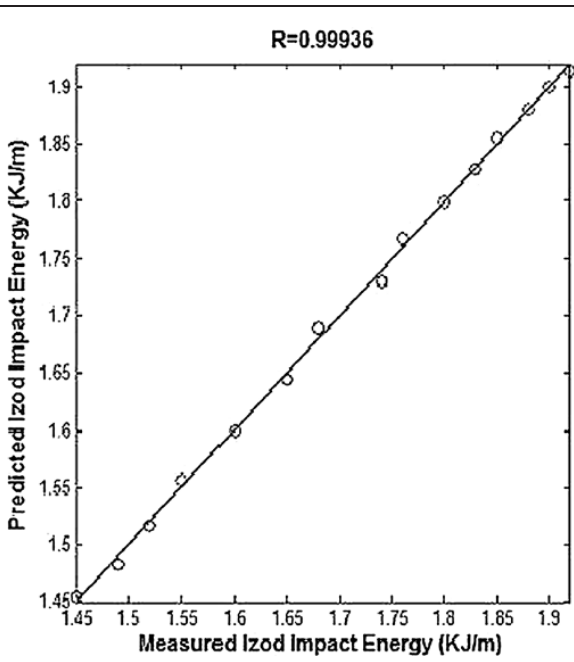

b

Figure 26 Izod notched impact energy (experimental results and ANN predictions) at $150 \mu \mathrm{m}$ and initial LDPE energy of $1.1 \mathrm{~kJ} / \mathrm{m}$. (a) Variation of Izod impact energy with filler content. (b) Prediction of Izod impact energy (experimental vs ANN predictions).

increased due to more energy required to propagate the crack. Izod notch is a measure of crack propagation. This is in line with that observed with wood polypropylene composites (Stark 1997).

Figures 26b, 27b, 28b and 29b show the artificial neural network predictions of the Izod notched impact energy of date palm wood fibre/LDPE composite for grain sizes of 150, 212, 250 and $300 \mu \mathrm{m}$. As the figures show, there is very good agreement with the artificial neural network predictions and experimental results.

Table 6 shows the ANN prediction summary for Izod notched impact energy. As shown in the table, the maximum correlation coefficient is 0.99955 , while the minimum is 0.99911 . Hence, the ANN predictions are very good.

\section{Conclusion}

From the analysis in this work, we have seen that the mechanical properties of polymer composite materials depend on the percentage of the filler content. Tensile properties of date palm wood flour/LDPE composites are slightly affected by weight fractions of date palm fibre. Generally, the neural network model predictions were in very good agreement with experimental results

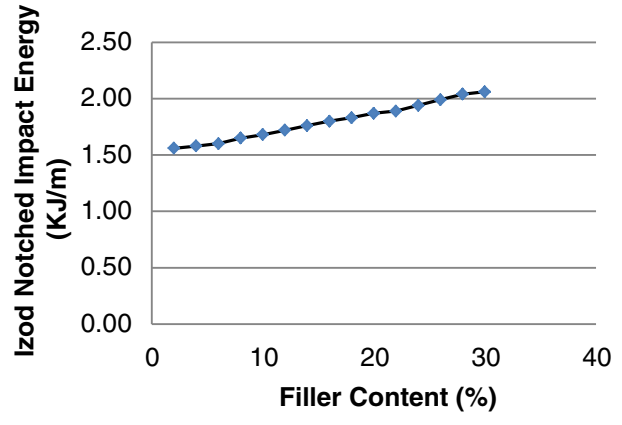

a

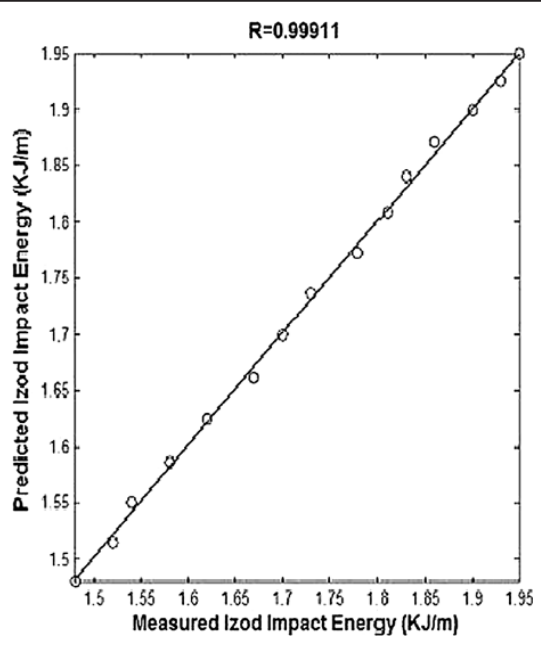

b

Figure 27 Izod notched impact energy (experimental results and ANN predictions) at $212 \mu \mathrm{m}$ and initial LDPE energy of $1.1 \mathrm{~kJ} / \mathrm{m}$. (a) Variation of lzod impact energy with filler content. (b) Prediction of lzod impact energy (experimental vs ANN predictions). 


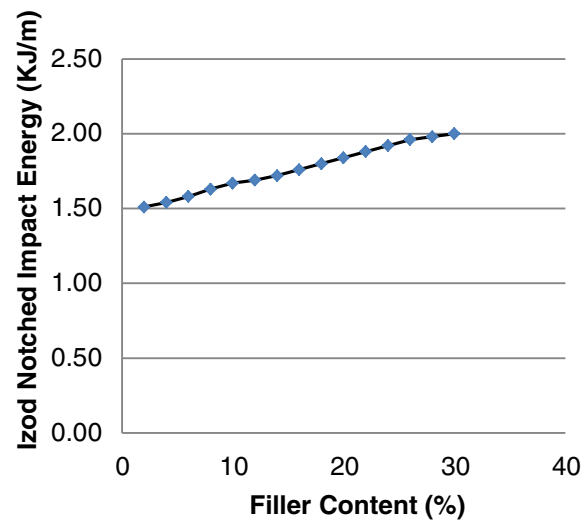

a

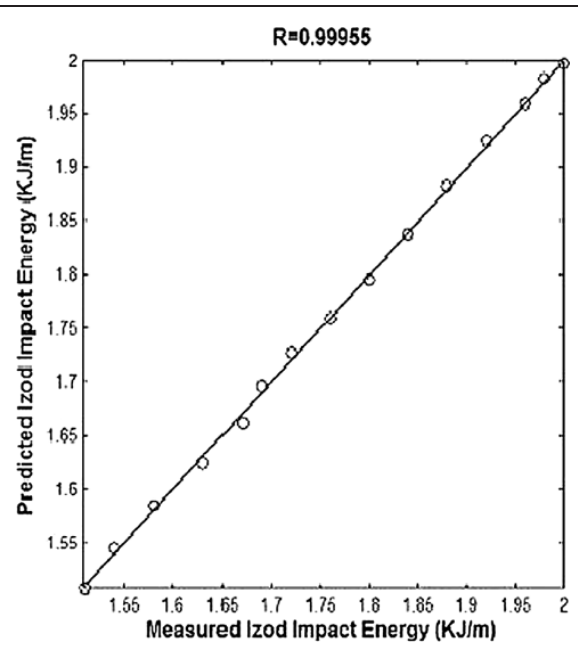

b

Figure 28 Izod notched impact energy (experimental results and ANN predictions) at $250 \mu \mathrm{m}$ and initial LDPE energy of $1.1 \mathrm{~kJ} / \mathrm{m}$. (a) Variation of Izod impact energy with filler content. (b) Prediction of Izod impact energy (experimental vs ANN predictions).

and hence could be used as substitute to costly timeconsuming experiments.

The ANN prediction was better than the results obtained by Nwobi-Okoye et al. (2013) and Umeonyiagu and Nwobi-Okoye (2013) who applied ANN for concrete strength (flexural and tensile) prediction. The results are similar to those obtained by Hassan et al. (2009) who applied ANN for prediction of some physical properties (porosity and density) and hardness of aluminium-copper/ silicon carbide composites. Also, the results are similar to those obtained by Sterjovski et al. (2005) who applied ANN for modelling the mechanical properties of steels in various applications and by Jiang et al. (2008) who used it to predict the mechanical and wear properties of short fibre reinforced polyamide composites.

Generally, the neural network models were bereft of the messy mathematics and statistical analysis required in building the regression model, while at the same time giving good model predictions. Hence, it would be preferable when the underlying mathematical structure behind the model predictions is irrelevant to the modeller/analyst, and model building is required quickly.

Determination of mechanical properties of materials is very important in engineering designs. Poor designs

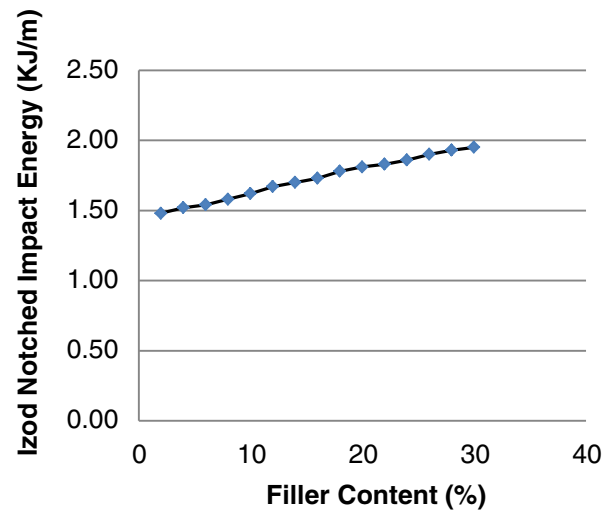

a

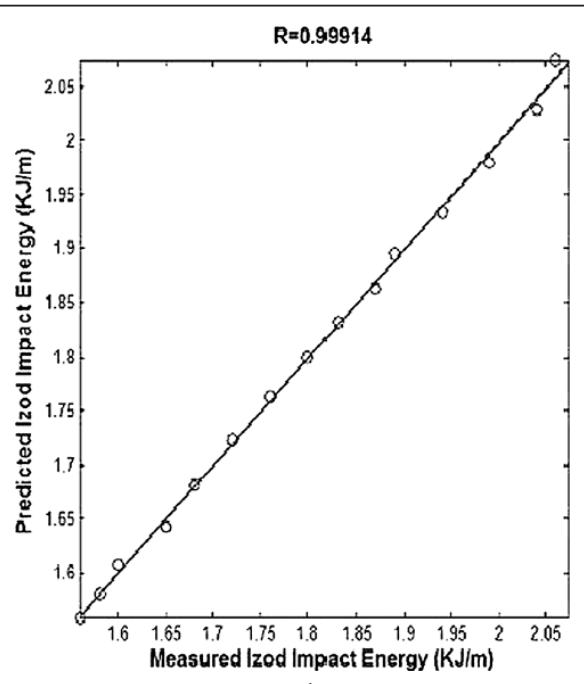

$\mathrm{b}$

Figure 29 Prediction of Izod notched impact energy (experimental results and ANN predictions) at $300 \mu \mathrm{m}$ and initial LDPE energy of $1.1 \mathrm{~kJ} / \mathrm{m}$. (a) Variation of Izod impact energy with filler content. (b) Prediction of Izod impact energy (experimental vs ANN predictions). 
Table 6 lzod notched impact energy prediction error summary

\begin{tabular}{llll}
\hline Grain size $(\boldsymbol{\mu m})$ & $\begin{array}{l}\text { Correlation } \\
\text { coefficient } \boldsymbol{R}\end{array}$ & Epoch & $\begin{array}{l}\text { Mean squared } \\
\text { error }(\mathrm{MSE})\end{array}$ \\
\hline 150 & 0.99936 & 13 & 0.00002936 \\
212 & 0.99911 & 23 & 0.00002470 \\
250 & 0.99955 & 21 & 0.00001687 \\
300 & 0.99914 & 13 & 0.00000237 \\
\hline
\end{tabular}

often lead to loss of lives and properties, and in addition to these, the economy is impacted negatively (AbdulQadir et al. 2011; Nigerian Institute for Oil Palm Research 2008; Olajumoke et al. 2009; Arum 2008). Often, poor composite mixtures and inadequate knowledge of the role of polymer composite mixture properties to its mechanical properties are to blame (Nwobi-Okoye et al. 2013; Umeonyiagu and Nwobi-Okoye 2013; Olajumoke et al. 2009; Arum 2008). It is obvious that neural network models will help in efficient and accurate determination of mechanical properties of date palm wood floor/LDPE polymer composite used in engineering applications.

Computational models using neural networks offer a very promising solution to the problem of polymer composite mechanical property prediction. Computational models are simple because they do not involve complex mathematical analysis. Hence, what the engineer needs is a good and reliable computer software and a matching hardware to do his analysis. The ubiquity of various computing platforms ranging from desktop PCs, laptops, palmtops, tablets, etc. means that such analysis is made even easier.

\section{Nomenclature, symbols and notations \\ $Y$ experimentally determined property \\ $\hat{Y}$ network prediction \\ $W$ neural network input weight \\ $g$ network activation function \\ $a_{i}$ neural network input activations \\ ${ }^{h} W$ network weighting function. \\ $t$ time}

\section{Competing interests}

The authors declare that they have no competing interests.

\section{Authors' contributions}

CUA conceived the study and participated in its design and coordination. MRG carried out the experiment. CCN-O carried out the ANN modeling participated in its design and coordination. ODO supervised the experiment and participated in its design and coordination. All authors read and approved the final manuscript.

\section{Author details}

'Department of Materials and Metallurgical Engineering, Nnamdi Azikiwe University, Awka, Nigeria. ${ }^{2}$ National Fertilizer Company of Nigeria, Onne, Nigeria. ${ }^{3}$ Anambra State University, Uli, Nigeria. ${ }^{4}$ Department of Chemical Engineering, Nnamdi Azikiwe University, Awka, Nigeria.
Received: 22 March 2014 Accepted: 24 June 2014

Published online: 30 August 2014

\section{References}

AbdulQadir, IM, Garba, ID, Eseigbe, E, \& Omofonmwan, El. (2011). Nutritional components of Date palm and its production status in Nigeria. International Journal of Agricultural Economics and Rural Development, 4(2), 83-89.

Ahmet, O, Murat, P, Erdogan, O, Erdogan, K, Naci, C, \& Bhatti, MA. (2006). Predicting the compressive strength and slump high strength polymer composite using artificial neural network. Constructions and Building Materials, 20(9), 769-775.

Akinro, AO, Ikumawoyi, OB, Yahaya, O, \& Ologunagha, NM. (2012). Environmental Impacts of Polyethylene generation and disposal in Akure City, Nigeria. Global journal of Science Frontier Research Agriculture and Biology, 12(3), 1-8.

Al-Kaabi, K, Al-Khanbashi, A, \& Hammami, A. (2005). Date palm fibers as polymeric matrix reinforcement: DPF/polyester composite properties. Polymer Composites, 26(5), 604-613.

Al-Khanbashi, A, Al-Kaabi, K, \& Hammami, A. (2005). Date palm fibers as polymeric matrix reinforcement: Fiber characterization. Polymer Composites, 26(4), 486-497.

Anderson, D, \& McNeill, G. (1992). Artificial neural networks technology, DACS State-ofthe-Art Report. New York, USA: United States Air force's Rome Laboratory.

Arum, C. (2008). Verification of Properties of Polymer composite Reinforcement Bars: Nigeria as a Case Study. Indoor and Built Environment, 17(4), 370-376.

Asilturk, l, \& Cunkas, M. (2011). Modelling and prediction of surface roughness in turning operations using artificial neural network and multiple regression method. Expert Systems with Applications, 38(5), 5826-5832.

ASTM. (2013a). ASTM D638: Standard test method for tensile properties of plastics.

ASTM. (2013b). ASTM D790: Standard test methods for flexural properties of unreinforced and reinforced plastics and electrical insulating materials.

ASTM. (2013c). ASTM D256: Standard test methods for determining the lzod pendulum impact resistance of plastics.

Atuanya, CU. (2013). The use of waste polyethylene bags as binder in the manufacture of wood composite. University of Benin: PhD Thesis, Unpublished.

Bendahou, A, Kaddami, H, Sautereau, H, Raihane, M, Erchiqui, F, \& Dufresne, A. (2008). Short Palm Tree Fibers Polyolefin Composites: Effect of Filler Content and Coupling Agent on Physical Properties. Macromolecular Materials and Engineering, 293, 140-148.

Berger, MJ, \& Stark, NM. (1997). Investigation of Species Effects in an Injection-MoldingGrade, Wood-Filled Polypropylene. Madison, Wisconsin, USA: The Fourth International Conference on Woodfiber-Plastic Composites, May 12-14.

Bilim, C, Atis, CD, Tanyildizi, H, \& Karahan, O. (2009). Predicting the compressive strength of ground granulated blast furnace slag concrete using artificial neural network. Advances in Engineering Software, 40(5), 334-340.

Bledzki, AK, \& Gassan, J. (1999). Composites reinforced with cellulose based fibers. Journal of Progress in Polymer Science, 24(2), 221-274.

Brent, E. (1996). Wood fiber- reinforced plastics in construction (pp. 79-81). Wisconsin: Conference on the use of recycled wood and paper in building applications.

Chatfield, C. (1993). Neural networks: Forecasting breakthrough or just a passing fad? International Journal of Forecasting, 9, 1-3.

Felix, JM, \& Gatenholm, P. (1991). The nature of adhesion in composites of modified cellulose fibers and polypropylene. Journal of Applied Science, 42(3), 620-609.

George, J, Sreekala, MS, \& Thomas, S. (2001). A review on interface modification and Characterization of a natural fiber reinforced plastic composites. Journal of Polymer Engineering and Science, 41(9), 1471-1485.

Hassan, AM, Alrashdan, A, Hayajneh, MT, \& Mayyas, AT. (2009). Prediction of density, porosity and hardness of aluminum-copper-based composite materials using artificial neural network. Journal of Materials Processing Technology, 209(2), 894-899.

Jiang, Z, Gyurova, L, Zhang, Z, Friedrich, K, \& Schlarb, AK. (2008). Neural network based prediction on mechanical and wear properties of short fibers reinforced polyamide composites. Materials and Design, 29(3), 628-637.

Kasperkiewicz, J, Racz, J, \& Dubrawski, A. (1995). HPC strength prediction using artificial neural network. Journal of Computing in Civil Engineering, 9(4), 2799-284.

Lee, SC. (2003). Prediction of polymer composite strength using artificial neural network. Eng. Structures, 25(3), 849-857.

Mahdavi, S, Kermanian, H, \& Varshoei, A. (2010). Comparison of mechanical properties of date palm fiber-polyethylene composite. BioResources, 5(4), 2391-2403.

Maier, HR, \& Dandy, GC. (2000). Neural networks for the prediction and forecasting of water resources variables: a review of modelling issues and applications. Environmental Modelling \& Software, 15, 101-124. 
McCulloch, WS, \& Pitts, W. (1943). A logical calculus of the ideas imminent in nervous activity. Bulletin and Mathematical Biophysics, 5, 115-133.

Mukherjee, A, \& Biswas, SN. (1997). Artificial neural networks in prediction of mechanical behavior of polymer composite at high temperature. Nuclear Engineering and Design, 178(1), 1-11.

Myers, GE, Chahyadi, IS, Coberly, CA, \& Ermer, DS. (1991). Wood flour/ polypropylene composites: Influence maleated polypropylene and process and composition variables on the mechanical properties. International Journal of Polymeric matter, 34(1), 23-30.

Nigerian Institute for Oil Palm Research. (2008). Nigerian Institute for Oil Palm Research (NFOR) in house research review (pp. 205-222).

Nwobi-Okoye, CC, Umeonyiagu, IE, \& Nwankwo, CG. (2013). Predicting the Compressive Strength of Concretes Made with Granite from Eastern Nigeria Using Artificial Neural Networks. Nigerian Journal of Technology (NIJOTECH), $32(1), 13-21$.

Olajumoke, AM, Oke, IA, Fajobi, AB, \& Ogedengbe, MO. (2009). Engineering Failure Analysis of a Failed Building in Osun State, Nigeria. Journal of Failure Analysis and Prevention, 9(1), 8-15.

Oretal, AWC, \& Kawashima, K. (2003). Neural Network Modeling of Confined Compressive Strength and Strain of Circular Polymer composite Columns. Journal of Structural Engineering, 129(4), 554-561.

Ozerdem, MS, \& Kolukisa, S. (2009). Artificial neural network approach to predict the mechanical properties of $\mathrm{Cu}-\mathrm{Sn}-\mathrm{Pb}-\mathrm{Zn}-\mathrm{Ni}$ cast alloys. Materials and Design, 30(3), 764-769.

Russell, SJ, \& Norvig, P. (2003). Artificial Intelligence: a modern approach. Upper Saddle River, New Jersey, USA: Pearson Educational Inc.

Sbiai, A, Kaddami, H, Fleury, E, Maazouz, A, Erchiqui, F, Koubaa, A, Soucy, J, \& Dufresne, A. (2008). Effect of the palm tree fibersfiber size on the physicochemical and mechanical properties of composites of epoxy and date. Macromolecular Materials and Engineering, 293, 684-691.

Shao-Yun, F, Xi-Qiao, F, Bernd, L, \& Yiu-Wing, M. (2008). Effect of particle size, particle/matrix interface adhesion and particle loading on mechanical properties of particulate-polymer composites. Composites: Part B, 39(2008), 933-961.

Stark, NM. (1997). Effect of Species and Particle Size on Properties of Wood-Flour-Filled Polypropylene Composites. San Diego, USA: Conference on Functional Fillers for Thermoplastics and Thermosets, December 8-10.

Sterjovski, Z, Nolan, D, Carpenter, KR, Dunne, DP, \& Norrish, J. (2005). Artificial neural networks for modelling the mechanical properties of steels in various applications. Journal of Materials Processing Technology, 170(3), 536-544.

Topcu, I, \& Saridemir, M. (2008). Predicting of compressive strength of polymer composite containing fly ash using artificial neural networks and fuzzy logic. Computational Material Science, 41(3), 305-311.

Umeonyiagu, IE, \& Nwobi-Okoye, CC. (2013). Predicting the Compressive Strength of Concretes Made with Washed Gravel from Eastern Nigeria Using Artificial Neural Networks. Journal of the Nigerian Association of Mathematical Physics, 23, 559-558.

Wazzan, AA. (2005). Effect of fiber orientation on the mechanical properties and fracture characteristics of date palm fiber reinforced composites. International Journal of Polymeric Materials and Polymeric Biomaterials, 54(3), 213-225.

Yang, HS, Kim, HJ, Park, HJ, Lee, BJ, \& Hwang, TS. (2006). Water absorption behavior and mechanical properties of lignocellulosic filler-polyolefin bio-composites. Composite Structures, 72(4), 429-437.

Zaini, MJ, Fuad, MYA, Ismail, Z, Mansor, MS, \& Mustafah, J. (1995). The effect of filler content and size on the mechanical properties of polypropylene/oil palm wood flour composites. Polymer International Journal,0959-8103/96 (Great Britain), 23(1), 34-38.

doi:10.1186/s40712-014-0007-6

Cite this article as: Atuanya et al:: Predicting the mechanical properties of date palm wood fibre-recycled low density polyethylene composite using artificial neural network. International Journal of Mechanical and Materials Engineering 2014 1:7.

\section{Submit your manuscript to a SpringerOpen ${ }^{\odot}$ journal and benefit from:}

- Convenient online submission

- Rigorous peer review

- Immediate publication on acceptance

- Open access: articles freely available online

- High visibility within the field

- Retaining the copyright to your article

Submit your next manuscript at $>$ springeropen.com 